\title{
House prices, lending standards, and the macroeconomy
}

\author{
Aino Silvo \\ University of Helsinki and HECER
}

Discussion Paper No. 407

January 2017

ISSN 1795-0562

HECER - Helsinki Center of Economic Research, P.O. Box 17 (Arkadiankatu 7), FI-00014 University of Helsinki, FINLAND,

Tel +358-2941-28780, E-mail info-hecer@helsinki.fi, Internet www.hecer.fi 


\title{
House prices, lending standards, and the macroeconomy*
}

\begin{abstract}
I study the link between house prices, lending standards, and aggregate over-investment in housing. I develop a model of the housing market where the credit market is affected by asymmetric information. Selection is towards less creditworthy borrowers. Asymmetric information coupled with deadweight costs of default can create endogenous boom-bust cycles in house prices. I show that lending standards are loose and the incentives for lessthan-creditworthy borrowers to apply for a loan are particularly strong, first, when future house values are expected to be high, which leads to high leverage of borrowers; and second, when safe interest rates are low, which implies low costs of borrowing. However, there are strong non-linearities in the relationship between borrowing incentives and economic fundamentals. The results shed light on incentive mechanisms that can help explain the developments in the U.S. housing market in the early 2000s. They also imply that loose monetary policy can have a direct impact on the stability of the housing market through the cost of borrowing and the opportunity cost of housing investment.
\end{abstract}

JEL Classification: E21, E32, E44, G14, G21

Keywords: Housing markets, adverse selection, lending standards, overinvestment, boom-bust

Aino Silvo

Department of Political and Economic Studies

University of Helsinki

P.O. Box 17 (Arkadiankatu 7)

FI-00014 University of Helsinki

FINLAND

e-mail: aino.silvo@helsinki.fi

* I thank Antti Ripatti and Tuomas Takalo for their guidance and suggestions. I also thank Marlène Isoré, Klaus Kultti, and participants at the HECER workshops, the Helsinki Macroeconomics Research Away Day workshop and the Finnish Economic Association Annual Meeting for useful comments. I am grateful for financial support from the Yrjö Jahnsson Foundation and the OP Group Research Foundation. 


\section{Introduction}

The housing boom of the early 2000's in the U.S. culminated in the subprime crisis of 2007-2009. The episode once again demonstrated the need to understand the dynamics of house prices, housing debt, and their links to the aggregate economy.

This paper presents a theoretical model of the housing market characterised by aggregate over-investment in housing that explores the incentives of households to take on debt over the house price cycle. The model can also accommodate an endogenous boom-bust cycle in house prices.

I show that there is a trade-off that creates a non-linear relationship between house prices and participation in the credit market. Expectations of high house prices first drive out the least creditworthy borrowers, as housing loans become more expensive. But eventually, the increasing capital gains available on housing investment can dominate the increasing cost of borrowing and draw back more and more risky borrowers. A low interest rate environment also fuels participation by non-creditworthy borrowers, as the cost of borrowing is less prohibitive. In this way, the model helps understand the behaviour of households during the housing boom of the early 2000s in the U.S., characterised by low interest rates and increasing house prices.

The data on housing markets in the U.S. have a few salient features. Figure 1 shows the co-movement of new residential mortgage originations, the mortgage delinquency rate, and subprime mortgage lending over the house price cycle in the United States in 1990-2015. Starting from 1998, house price appreciation picked up and peaked in 2006 at $30 \%$ above trend before falling dramatically.

This dramatic boom-bust cycle in house prices was, however, accompanied and even overshadowed by a surge in mortgage originations. They grew from almost $70 \%$ below the sample mean in 1990 to $120 \%$ above mean in 2003. The most impressive growth in originations coincides with the period from 2000 to 2003, at the onset of the housing boom.

At the same time, the share of subprime mortgage origination was relatively stable at around $10 \%$ of all mortgage originations until 2004, after 


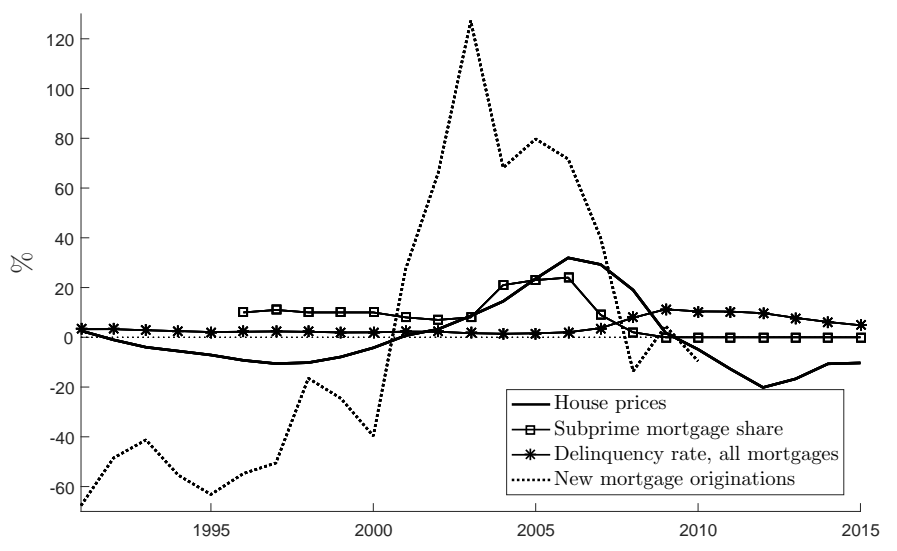

Figure 1: Mortgage lending, delinquencies, and the house price cycle. House prices: \%-deviation from a linear trend; source: S\&P Case-Shiller U.S. National Home Price index. Subprime mortgages: \% share of total mortgage originations; source: Inside Mortgage Finance, collected from the Financial crisis inquiry report (2011) for years 1996-2008 and Zibel and Andriotis (2015) for years 2009-2014. Delinquency rate: \% share of all single-family residential mortgages; source: Board of Governors of the Federal Reserve System. New mortgage originations: total volume of new single-family residential mortgage originations, 1990-2010, \%-deviation from sample mean; source: U.S. Federal Housing Finance Agency.

which it rapidly expanded, peaked in 2006 with house prices, and collapsed to virtually zero from 2009 onwards. Meanwhile, the delinquency rate was stable at sligtly above $2 \%$ until 2006 . As house prices started to fall, delinquencies on mortgages started increasing and reached $11 \%$ in 2009. They have remained elevated since then. This development in mortgage delinquencies following the housing boom has widely been referred to as the U.S. foreclosure crisis (see e.g. the Financial Crisis Inquiry Commission (2011)).

In this paper, my aim is not to explain why this increase in supply happened, or to take a stance on whether it was welfare-improving or not. ${ }^{1}$ Rather, I abstract away from the details of the supply side and assume it accommodates the demand for loanable funds. I study, first, the incentives on the borrower side to enter the loan market and subsequently to potentially default on the loan, given house prices. Second, I analyse how these entry and default incentives can feed back into prices to create a

\footnotetext{
${ }^{1}$ The surge in subprime lending is related to a loosening of lending standards, as argued e.g. by the Financial Crisis Inquiry Commission (2011). As documented in their report, the supply of subprime loans surged starting from the late 1990's as a result of increased securitisation and, at the extreme, even fraudulent lending practices.
} 
boom-bust cycle in the housing market.

I analyse these mechanisms using a model of asymmetric information in the credit market. I model the housing market in a setting where the intermediation of loans is inefficient because of an adverse selection problem, modelled after the classic framework of De Meza and Webb $(1987,1990)$. I assume fundamental house values are exogenous and heterogenous, but endogenise the sales price of housing. This price reflects the true fundamental value of the housing stock, and there is no bubble element.

In order to talk about potentially harmful overborrowing, there has to be a market failure that allows households to take on too much debt from a social perspective. In such a context, overborrowing is naturally defined as a deviation from a socially efficient equilibrium. Similarly, a loosening or tightening of lending standards can be modelled as a deviation from the first-best in lenders' optimal decisions in terms of to whom, and at what price, loans should be granted. ${ }^{2}$

In the model presented in this paper, all households are subject to two shocks: a shock to house value, and an income shock. The former is observable by all agents, whereas the latter is private information to the borrower. The households also face two fundamental choices. First, they must decide whether to buy or rent a home; they may need to borrow to finance housing purchases, but their future income is uncertain at the time of purchase. Second, after income uncertainty is resolved, they can choose to default on their debt if they have any. Default acts as a form of insurance against adverse house value and income shocks, induced by market incompleteness and limited liability, but carries a deadweight loss cost.

Optimal default decisions are affected by the joint probability of the two shocks. Consequently, borrowers differ by their default risk in a way that is unobservable to lenders. This particular information structure leads to over-investment in equilibrium, and subprime borrowers are defined as the set of borrowers who do get a loan under asymmetric information, but

\footnotetext{
${ }^{2}$ The term "lending standards" is used here to describe the behaviour of lenders under asymmetric information, relative to their actions under symmetric information. The term is used in a similar way in a host of literature concerning informational asymmetries in the credit market; see e.g. Dell'Ariccia and Marquez (2006) and the references therein.
} 
would not if their types were publicly observable.

Asymmetric information gives rise to endogenous credit "constraints": some households self-select out of the credit market because borrowing would be too expensive for them, given their income prospects. The households are not constrained by any hard limit on the amount of debt they can or are allowed to take on, but rather by the price of borrowing. There can still be overborrowing with respect to first-best, if too few choose to stay out of the loan market.

Then, I extend the model to allow for an endogenous cycle in the house price, even when fundamentals are unchanged, by introducing an aggregate demand complementarity in the households' preference for housing consumption. This feature, coupled with large enough deadweight costs on defaults, can create a deterministic boom-bust cycle even in the absence of aggregate uncertainty. These elements capture, first, the "hype" surrounding homeownership during the boom phase, and subsequently, the foreclosure wave that induces the bust phase.

The main results of this paper are two-fold. The first set of results comes from a comparative statics exercise that explores participation and default incentives in the cross-section of households. The second set focuses on incentives over time to explain a boom-bust cycle in the housing market.

First, as the main contribution of this paper, I show using a comparative statics exercise that there is a non-linear relationship between expected house values and participation in the credit market. When future house values, and thus prices, are expected to be low, participation is high. As expected house values rise, the types with the lowest expected income first opt out of the market because housing becomes more expensive. Eventually, expected capital gains become so attractive that the risky types enter the market again as expected future house values rise further. Because the borrowers are more levered, default becomes optimal if they are hit by an adverse combination of income and house value shocks.

The relationship between safe interest rates and credit market participation is monotone: lower interest rates attract more borrowers, as outside returns and borrowing costs are both low. I also demonstrate that tightening default legislation that affects all borrowers similarly is not an effective 
way to curb overborrowing. An effective policy must target incentives of different types directly.

Second, I show that the model is capable of accommodating a deterministic cycle in house prices, and that qualitetively - in terms of relative magnitudes and the timing of the cycles - these dynamic patterns match the observed cycles in the U.S. data very well.

These results complement the evidence in a series of influential empirical studies by Mian and Sufi $(2009,2011)$ and Mian et al. (2013). The authors find evidence for a credit supply driven mortgage lending boom, where lenders expanded their supply of mortgage lending and relaxed their lending standards in the run-up to the subprime crisis of 2007-2009. The shift in supply was tightly connected to the expansion of mortgage securitisation since the early 2000's. Dell'Ariccia and Marquez (2012) argue that the relaxation of lending standards was partly explained by an increase in credit demand, when controlling for supply-side factors such as house prices and securitisation.

This paper is linked to a growing body of literature on the interactions of house prices prices and aggregate consumption. Iacoviello (2005), Kiyotaki et al. (2011), Iacoviello and Pavan (2013), and Guerrieri and Iacoviello (2014) study aggregate housing debt and the interaction between house prices and consumption. Kaplan and Violante (2014) and Gorea and Midrigan (2015) look at the aggregate implications of wealth and liquidity heterogeneity and the marginal propensity of constrained agents to consume out of housing wealth. Favilukis et al. (2017) explore how a relaxation of financial constraints can lead to a house price boom. However, these papers do not explain or motivate why some borrowers are constrained. In contrast to these papers, my focus is on formulating explicitly the incentives for entry to the credit market as well as default incentives. Under private types, a credit constraint on households arises endogenously as the least-creditworthy borrowers self-select out of the credit market given the equilibrium terms on borrowing.

This research also connects to recent quantitative models of the housing market where mortgage borrowers can strategically default, such as Corbae and Quintin (2015), Guler (2015), Arslan et al. (2015), and Elenev et al. 
(2016). These papers are more quantitative in nature than this paper, but their results are similar to mine: households have the strongest incentives to default when they both face an adverse income shock and their home equity is negative. However, unlike this paper, they do not consider private information, with the exception of Guler (2015).

The paper also contributes to the study of risk-averse agents and adverse selection in macroeconomic literature. A recent strand of literature has attempted to explain inefficiencies in aggregate investment by exploiting an adverse selection framework. Eisfeldt (2004), House (2006), Morris and Shin (2012), Takalo and Toivanen (2012), Jokivuolle et al. (2014) and Bigio (2015) look at investment in entrepreneurial projects, or the financing of capital production, in general equilibrium when the financing is affected by asymmetric information on project quality. On the supply side, Dell'Ariccia and Marquez (2006) find that increasing asymmetric information across lenders can lead to a tightening of lending standards, as lenders screen loan applicants better.

The model presented in this paper applies the adverse selection framework of De Meza and Webb (1987, 1990), and builds upon the general equilibrium framework of House (2006), although he focuses on risk-neutral entrepreneurs who invest in capital investment projects. Guler (2015) studies an economy with adverse selection and strategic default in the housing market, but contrary to this paper, argues that adverse selection has lead to credit rationing rather than over-lending in the housing market, and that the run-up to the subprime crisis can be explained with an increase in information symmetry and thus an increase in efficiency of credit intermediation, rather than an exacerbation of a market failure.

Finally, this paper connects to an old literature in macroeconomics and macro-finance that focuses on deterministic and endogenous cycles in investment. Examples include Azariadis and Smith (1998), Matsuyama (2007); Matsuyama et al. (2016), Favara (2012), Beaudry et al. (2015), and Azariadis et al. (2016). They all rely on some combination of demand complementarities and costs of default to generate an endogenous cycle. I am not aware of a paper that would apply these ideas to investment in housing. 
The remainder of the paper is organised as follows. Section 2 describes the model economy. Section 3 solves for the credit market equilibrium under symmetric and asymmetric information. Section 4 describes the timing of events and characterises the equilibrium of the aggregate economy. Section 5 explores the link between house prices, interest rates, and the selection into the housing market through a comparative statics exercise. Section 6 extends the baseline model to accommodate an endogenous boom-bust cycle in house prices, and discusses the implications of such a cycle. Finally, Section 7 concludes.

\section{The model}

In this section, I describe in detail the economic environment of the model. First, I describe the stochastic structure of the economy and the information sets of each agent. Then, I formulate the problems of each type of agent.

\subsection{Description of the economy}

The economy consists of three types of agents: consumers, lenders, and real estate agents. The consumers have a finite lifetime, and they consume housing services and other consumption goods and receive an endowment income. The lenders extend loans to consumers in a perfectly competitive credit market. The real estate agents buy housing from exiting consumers as well as from lenders who acquire foreclosed housing, refurbish them, and re-sell them to newborn consumers.

There is a continuum of mass one of households which consist of consumers who are risk averse. Each consumer only lives for two periods. Each period, a new generation of consumers enters as the previous one exits, so that the total mass of consumers stays constant. Each consumer receives an exogenous income in both periods of her life. In the first period, she must make a tenure choice of either buying or renting a unit of housing. In order to buy a house, she needs a loan from a banker. In the second period, she consumes housing services and other consumption 


\begin{tabular}{l|cc}
$q_{1} \backslash y_{1}$ & $y_{H}$ & $y_{L}$ \\
\hline$q_{H}$ & $\pi \phi$ & $(1-\pi) \phi$ \\
$q_{L}$ & $\pi(1-\phi)$ & $(1-\pi)(1-\phi)$
\end{tabular}

Table 1: Joint distribution of endowment $y_{1}$ and house value $q_{1}$ in $t=1$

goods. I assume that debt is not perfectly enforceable, so that the borrower can default on the loan in the second period instead of repayment.

Consider a consumer who lives for two periods, $t=0,1$. A consumer who wishes to become a home-owner buys housing $h$ in $t=0$ at a unit price $q_{0}$. At the time of the purchase, the value of the house in $t=1\left(q_{1}\right)$ is uncertain. It can be $q_{1}=q_{H}$ with probability $\phi$, or $q_{1}=q_{L}$ with probability $1-\phi$, with $q_{H}>q_{0}>q_{L} \geq 0$.

Similarly, the endowment of the consumer in period $t=1$ is $y_{1} \in\left\{y_{H}, y_{L}\right\}$ with $y_{H}>y_{0}>y_{L}>0$. The probability of receiving $y_{H}$ and $y_{L}$ are $\pi$ and $1-\pi$, respectively. The combination of these two sources of uncertainty may trigger a default by homeowners. The joint distribution of $y_{1}$ and $q_{1}$ is shown in Table 1.

The consumers differ by their probability of realising a high endowment $y_{H}$ : there is a continuum of types $\pi \in[0,1]$. This means that different borrowers face a different risk of low income $y_{L}$, and thus, a higher risk of potential default. The consumers only differ in the probability $\pi$ they face; otherwise, they have the same preferences, and the same support for the income distribution $y_{1} \in\left\{y_{H}, y_{L}\right\}$, and the same stochastic process and support for the housing value shock on $q_{1}$.

The type $\pi$ is private information observed only by the consumer herself, and not by other agents in the economy. Lenders and real estate agents know the distribution of $\pi, F(\pi)$, which is time-invariant.

There is also a continuum of mass one of lenders, who are risk neutral. They have access to an infinitely elastic supply of funds (for example, through the international financial market). The lenders grant loans to borrowers, collect loan repayments, and consume their profits. The credit market is perfectly competitive and anonymous, and the loans are oneperiod loans. 
Finally, there is a continuum of mass one of real estate agents, who are risk neutral. They buy the housing stock from each exiting generation of households, as well as used housing held by lenders, refurbish it at no cost, and sell or rent it to the entering generation.

\subsection{The credit market}

There is a competitive credit market where households can apply for loans from a continuum of atomistic lenders. The loan contract consists of a loan $l_{0}$ and a repayment schedule given by $\min \left\{\left(1+r_{0}\right) l_{0}, q_{1} h+\xi y_{1}\right\}$. The lender observes the realisation of the house value $q_{1}$ and the income $y_{1}$ after the contract has been agreed upon, but before the loan repayment is scheduled to be made. In the event of default, the lender seizes the house and also has recourse to a fraction $0<\xi<1$ of the borrower's income, $y_{1}$. If there is no default, the lender collects the loan repayment $\left(1+r_{0}\right) l_{0}$.

The credit market equilibrium is described in Section 3.

\subsection{The household problem}

Assume that there is a fixed aggregate stock of housing $\bar{h}$. Each individual must occupy a housing unit of equal size $h$, which provides a flow of housing services; each unit is ex-ante identical. Since income $y_{0}$ is equal across households as well, the assumption of fixed $h$ means that, importantly, the ratio of housing to income $\frac{h}{y_{0}}$ - or equivalently leverage - is constant across borrowers. ${ }^{3}$ The individual problem is to make the tenure choice over owning or renting a house. Given this choice, the consumption pattern in the second period is determined. I abstract from the choice over how much housing to acquire.

Consider a generation of individuals born in period $t=0$. Both a homeowner and a tenant receive an exogenous income $y_{t}$ in both periods. If the individual chooses to rent, she can earn the safe market rate $\bar{r}$ on her

\footnotetext{
${ }^{3}$ The strict assumptions of identical $y_{0}$ and $h$ are made for convenience, but it is the equal leverage ratio that is crucial. This assumption is important in equilibrium, because it prevents borrowers from signaling their types to lenders by choosing different house sizes. The implications of this assumption is discussed in more detail in Section 3.3.1.
} 
savings $a_{0}$, while paying a rent $s_{t}$ per unit of housing in the second period. In contrast, a home-owner in the first period takes out a loan $l_{0}$ to acquire housing $h$ at a unit price $q_{0}$.

In the first period, there is no consumption; the endowment received in $t=$ 0 is invested either into housing or a safe deposit. The budget constraint of a homeowner and a tenant are then:

\begin{tabular}{ll}
\hline Home-owner & $q_{0} h=y_{0}+l_{0}$ \\
\hline Tenant & $a_{0}=y_{0}$ \\
\hline
\end{tabular}

At the beginning of the second period, the income $y_{1}$ is realised, and the home-owner makes the decision of whether or not to default. If there is no default, she consumes and pays back the loan principal and interest. However, if she chooses to default on the loan, the lender seizes the house and the fraction $\xi y_{1}$ of the income, and the borrower must convert into a tenant, paying rent $s_{1}$ on housing. A defaulting borrower also faces a deadweight loss cost of default $\kappa \geq 0$. It can be interpreted as capturing various real costs associated with default, such as legal costs or loss of access to credit markets.

If the individual chooses to rent a house, she pays a unit rent $s_{1}$ in $t=1$, and can save or borrow $a_{0}$ in period 0 with the market interest rate $\bar{r}$. In the second period, she consumes her endowment and her savings.

The price of the consumption good acts as numeraire and is normalised to unity.

The ex-post budget constraints of the household in the second period of their life, $t=1$, are:

\begin{tabular}{ll}
\hline Home-owner & \\
No default & $c_{1}+\left(1+r_{0}\right) l_{0}=y_{1}+q_{1} h$ \\
Default & $c_{1}+s_{1} h=(1-\xi) y_{1}-\kappa$ \\
\hline Tenant & $c_{1}+s_{1} h=y_{1}+(1+\bar{r}) a_{0}$ \\
\hline
\end{tabular}

The consumer derives utility from consuming housing services and other goods in the second period of her life, captured by the utility function $u(c)+\chi_{i} v(h)$, where $i=h, r$ designates a home-owner $(h)$ or tenant $(r)$. 
The utility function is separable in housing services and other goods, and I assume $u(\cdot)$ increasing and concave: $u^{\prime}(\cdot)>0, u^{\prime \prime}(\cdot)<0$. Utility from housing services satisfies $v(\cdot)>0$ and $v(0)=0$. In addition, homeowners enjoy a utility premium on housing services: $\chi_{h}$ is normalised to 1 for $i=h$, and $\chi_{r}=\chi<1$ for tenants. ${ }^{4}$

The value function of a consumer of type $\pi$ in $t_{0}$ who becomes a homeowner is:

$$
\begin{aligned}
V_{H}(\pi) & =E\left[u\left(c_{1}\left(y_{1}, q_{1}\right)\right)+v(h) \mid \pi\right] \\
& =p(\pi) E\left[u\left(c_{n d}\left(y_{1}, q_{1}\right)\right)+v(h) \mid \pi\right]+(1-p(\pi)) E\left[u\left(c_{d}\left(y_{1}\right)\right)+\chi v(h) \mid \pi\right]
\end{aligned}
$$

$$
\begin{array}{ll}
\text { s.t. } & q_{0} h=y_{0}+l_{0} \\
& c_{n d}\left(y_{1}, q_{1}\right)=y_{1}+q_{1} h-\left(1+r_{0}\right) l_{0} \\
& c_{d}\left(y_{1}\right)=(1-\xi) y_{1}-\kappa-s_{1} h
\end{array}
$$

where $c_{n d}$ denotes period 1 consumption in case of no default, and $c_{d}$ period 1 consumption in case of default. Both are functions of the period 1 income $y_{1}$. The consumption under no default also depends on the house value $q_{1}$.

$p(\pi)$ is the individual ex-ante probability of not defaulting in $t=1$, given the home-owner's type $\pi$. It is an equilibrium object, for which the expression is derived in Section 3.1.

Substituting the period 0 budget constraint (2) into the no-default budget constraint (3) and rearranging yields the intertemporal budget constraint

$$
c_{n d}\left(y_{1}, q_{1}\right)=y_{1}+(1+r) y_{0}+\Delta q h-r_{0} q_{0} h
$$

where $\Delta q \equiv q_{1}-q_{0}$ equals the capital gain on the house. The term $r_{0} q_{0}$ is the user cost of housing borne in the second period.

\footnotetext{
${ }^{4}$ Since the housing choice is a binary one (own/rent), the separability assumption is not crucial, but it is analytically convenient. For the same reason, the shape of $v$ is not important as long as an owner enjoys a utility premium relative to a tenant.
} 
The value function of a consumer who becomes a tenant is:

$$
\begin{aligned}
V_{R}(\pi) & =E\left[u\left(c_{r}\left(y_{1}\right)\right)+\chi v(h) \mid \pi\right] \\
& =\pi u\left(c_{r}\left(y_{H}\right)\right)+(1-\pi) u\left(c_{r}\left(y_{L}\right)\right)+\chi v(h) \\
\text { s.t. } & c_{r}\left(y_{1}\right)=y_{1}+(1+\bar{r}) y_{0}-s_{1} h
\end{aligned}
$$

An individual chooses to buy a house and become a home-owner if and only if $V_{H}(\pi) \geq V_{R}(\pi)$. The trade-off that the individual faces is the higher income in the good state, in the form of the risky capital gain on housing, as well as enjoying the utility premium on housing services, as a home-owner, versus the less risky consumption granted by the safe return on savings as a tenant.

The value function of a household of type $\pi$ in the first period is thus:

$$
V(\pi)=\max \left\{V_{H}(\pi), V_{R}(\pi)\right\}
$$

\subsection{The real estate market}

There is also a competitive real estate market, where a continuum of atomistic real estate agents act. In each period, a representative real estate agent buys housing both from successful exiting home-owners in the second period of their lifetime, and from lenders who have seized the houses of defaulting home-owners. The real estate agents refurbishes the housing stock at no cost, and sells it to the new, entering generation.

I assume that the whole housing stock, both owner-occupied and rental housing, are subject to the same distribution of value shocks. Then, in any given period, a fraction $\phi$ ends up as high value $\left(q_{H}\right)$, and a fraction $1-\phi$ is low value $\left(q_{L}\right)$.

Competition drives the profits of the real estate agents to zero, so that the sales price of the refurbished housing to a generation entering in period $t$ is:

$$
q_{t}=\phi q_{H}+(1-\phi) q_{L}
$$

The real estate agents also rent part of the housing stock to the defaulting 
homeowners whose houses have been foreclosed, and households who have chosen to rent, in any given period $t$ at a rental rate of $s_{t}$, and bear the user cost $r_{t-1} q_{t-1}$ per unit of housing. Perfect competition then drives the rental rate down to equal the user cost of housing:

$$
s_{t}=r_{t-1} q_{t-1}
$$

\section{Credit market equilibrium}

The credit market intermediates funds to consumers who wish to become homeowners but who cannot self-finance their housing investment. Under the assumptions made in Section 2, all consumers receive an identical endowment in the first period of their life, so that all (or none) of those who wish to buy a house must borrow.

In this section, I characterise the credit market equilibrium by focusing on a Perfect Bayesian equilibrium concept. I derive the optimal default decision of the borrower, given the loan amount and repayment, and the terms of the loan contract offered by the lender, given the ex-ante expectation of default in the borrower pool. The equilibrium in the loan market in the first period of a given generation is then characterised by the terms of the credit contract and a set of borrowers who accept this contract, given the ex-ante default probabilities. I analyse the equilibrium both under symmetric and asymmetric information in order to highlight the externality that causes over-investment.

\subsection{Optimal default decision}

In the second period, a home-owner will choose not to default if and only if:

$$
u\left(c_{n d}\left(y_{1}, q_{1}\right)\right)+v(h) \geq u\left(c_{d}\left(y_{1}\right)\right)+\chi v(h)
$$


for a given realisation $\left(y_{1}, q_{1}\right)$. Then, the ex-ante probability of no default, conditional on the borrower type $\pi$, is:

$$
\begin{aligned}
\operatorname{Pr}\{\text { 'no default' } \mid \pi\} & =\operatorname{Pr}\left\{u\left(c_{n d}\left(y_{1}, q_{1}\right)\right)+v(h) \geq u\left(c_{d}\left(y_{1}\right)\right)+\chi v(h) \mid \pi\right\} \\
& \equiv p(\pi) .
\end{aligned}
$$

This is equivalent to:

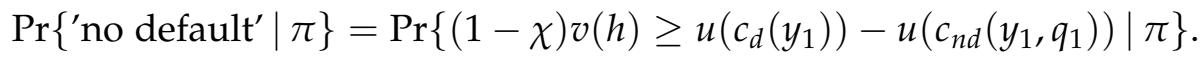

In other words, the homeowner will not default if the utility premium from owner-occupied housing relative to tenant-occupied housing is greater than the utility in terms of consumption insurance acquired by defaulting.

Because utility is increasing in consumption, but more so in the no-default state (because only a fraction $1-\xi$ can be consumed in the default state), the right hand side of this inequality is decreasing in $y_{1}$. Thus the probability of no default, $p(\pi)$, is increasing with the likelihood of high income, $\pi$.

Correspondingly, the conditional default probability is $1-p(\pi)$, which is decreasing in $\pi$.

\subsection{Credit market equilibrium under symmetric information}

Assume that there is symmetric information about borrower types, so that a lender can observe each individual borrower's type $\pi$, and subsequently, also their individual ex-ante default probability $p(\pi)$. Then, he will offer a different loan contract $\mathcal{C}_{\pi}$ characterised by an interest rate $r(\pi)$ to each type $\pi$. The symmetric information equilibrium thus provides the firstbest benchmark for the credit market, since each consumer faces individual loan terms that reflect their true riskiness, or type $\pi$.

Each potential borrower will demand a loan of equal size: $l_{0}=q_{0} h-y_{0}$. Then the interest rate offered to each potential borrower fully characterises 
a contract $\mathcal{C}_{\pi}$. The expected return on such a loan is

$$
E \Pi(\pi)=p(\pi)(1+r(\pi)) l_{0}+(1-p(\pi)) E\left[q_{1} h+\left.\xi y_{1}\right|^{\prime} \text { default', } \pi\right]
$$

where in case of no default, the lender receives the repayment of the loan amount and interest, and in case of default, recovers the house and the fraction $\xi$ of income of the borrower.

Perfect competition ensures that the expected return on each individual loan is equal to the opportunity cost of the funds, $1+\bar{r}$ :

$$
\begin{aligned}
& p(\pi)[1+r(\pi)] l_{0}+(1-p(\pi)) E\left[q_{1} h+\xi y_{1} \mid \text { 'default', } \pi\right]=(1+\bar{r}) l_{0} \\
& \Leftrightarrow 1+r(\pi)=\frac{1+\bar{r}}{p(\pi)}-\frac{1-p(\pi)}{p(\pi)} \frac{E\left[q_{1} h+\xi y_{1} \mid \text { 'default', } \pi\right]^{\prime} .}{l_{0}} \text {. }
\end{aligned}
$$

The term $E\left[q_{1} h+\xi y_{1} \mid\right.$ 'default', $\left.\pi\right]$ gives the lender's expected compensation in case of default, given that default occurs and the borrower's type is $\pi$. Because borrowers choose when to default strategically, the state $\left(y_{1}, q_{1}\right)$ under which default occurs, and thus also the lender's return in the default state, is endogenous and depends on the type. The no-default probability is increasing in the probability of a favourable income realisation, $\pi$. This implies that the individual rate $1+r(\pi)$ is decreasing in $\pi$ : $\frac{\mathrm{d} r(\pi)}{\mathrm{d} \pi}<0$.

Given the offered rate $r(\pi)$, a borrower accepts the loan and becomes a homeowner if $V_{H}(\pi) \geq V_{R}(\pi)$, as given by equations (1) and (6); otherwise, she becomes a tenant. High $\pi$ borrowers enjoy lower interest rates on their loans. At the limit, the borrower with $\pi=1$ faces no income risk, but only a risk of the house losing its value.

Denote by the superscript $F B$ (for "first-best") variables under the symmetric information equilibrium. Given the rate $r(\pi)$ and using the budget constraints (4) and (5), the first-best consumption of a type- $\pi$ homeowner in the no-default $(n d)$ and default $(d)$ states, respectively, are:

$$
\begin{aligned}
c_{n d}^{F B}\left(y_{1}, q_{1} ; \pi\right) & =(1+r(\pi)) y_{0}+y_{1}+\Delta q h-r(\pi) q_{0} h \\
c_{d}^{F B}\left(y_{1} ; \pi\right) & =(1-\xi) y_{1}-\kappa-s_{1} h,
\end{aligned}
$$


and the consumption of a tenant is:

$$
c_{r}^{F B}\left(y_{1} ; \pi\right)=y_{1}+(1+\bar{r}) y_{0}-s_{1} h
$$

Proposition 1 The credit market equilibrium under symmetric information is characterised by a set of contracts $\mathcal{C}_{\pi}=\left\{l_{0}, \min \left\{(1+r(\pi)) l_{0}, q_{1} h+\xi y_{1}\right\}\right\}$ and a cut-off type $\hat{\pi}^{F B} \in[0,1]$ such that all individuals with $\pi \geq \hat{\pi}^{F B}$ accept $\mathcal{C}_{\pi}$ and become home-owners, and all individuals with $\pi<\hat{\pi}^{F B}$ become tenants, and the lenders break even in expectation for every type $\pi$ individually.

Proof In Appendix A.1.

The first-best, or efficient, cutoff type $\hat{\pi}^{F B}$ is just indifferent between buying and renting, and is characterised by:

$$
\begin{aligned}
& V_{H}^{F B}\left(\hat{\pi}^{F B}\right)=V_{R}^{F B}\left(\hat{\pi}^{F B}\right) \\
\Leftrightarrow \quad & E\left[p\left(\hat{\pi}^{F B}\right)\left[u\left(c_{n d}^{F B}\left(\hat{\pi}^{F B}\right)\right)+v(h)\right]+\left(1-p\left(\hat{\pi}^{F B}\right)\right)\left[u\left(c_{d}^{F B}\right)+\chi v(h)\right] \mid \hat{\pi}^{F B}\right]= \\
& E\left[u\left(c_{r}\right)+\chi v(h) \mid \hat{\pi}^{F B}\right] \\
\Leftrightarrow & p\left(\hat{\pi}^{F B}\right)=\frac{E\left[u\left(c_{r}^{F B}\right)-u\left(c_{d}^{F B}\right) \mid \hat{\pi}^{F B}\right]}{E\left[u\left(c_{n d}^{F B}\left(\hat{\pi}^{F B}\right)\right)-u\left(c_{d}^{F B}\right)+(1-\chi) v(h) \mid \hat{\pi}^{F B}\right]}
\end{aligned}
$$

The credit market equilibrium under symmetric information is efficient and establishes a first-best benchmark. It is efficient because the cost of borrowing of each type correctly reflects their true default risk. The implications of this feature are further discussed in Section 5.

\subsection{Credit market equilibrium under asymmetric information}

Now return to the assumption that a borrower's type is unobservable to the lender. I focus on a particular perfect Bayesian equilibrium characterised by pooling of borrowers.

Again, all borrowers demand a loan of equal size, $l_{0}=q_{0} h-y_{0}$. However, now $-\pi$ borrowers have the incentive to mimic high- $\pi$ borrowers in order to get a loan with favorable terms because of the limited liability in case of default. There exists now an equilibrium, characterised by a cut-off, in which the banker lends to all borrowers above the cut-off, and charges an common interest rate $r_{0}$ from all borrowers, such that he makes a non-negative 
expected profit in expectation on the pool of loans. The equilibrium is characterised by a pooling contract $\mathcal{C}=\left\{l_{0}, \min \left\{\left(1+r_{0}\right) l_{0}, q_{1} h+\xi y_{1}\right\}\right\}$.

The equilibrium interest rate is determined by the break-even condition of the lenders. The expected return of a banker who charges an interest rate $r_{0}$, given the pool of loan applicants characterised by the cutoff $\hat{\pi}$, is given by:

$$
E \Pi\left(r_{0}\right)=E[p(\pi) \mid \pi \geq \hat{\pi}]\left(1+r_{0}\right) l_{0}+E\left[(1-p(\pi))\left(q_{1} h+\xi y_{1}\right) \mid \pi \geq \hat{\pi}\right] .
$$

In equilibrium, the competition drives the return on the loan down to equal the market rate, or the opportunity cost of the funds. The equilibrium interest rate offered to all loan applicants, $r^{*}$, is then given by:

$$
\begin{aligned}
E \Pi\left(r_{0}\right) & =(1+\bar{r}) l_{0} \\
\Leftrightarrow \quad 1+r_{0} & =\frac{1+\bar{r}}{E[p(\pi) \mid \pi \geq \hat{\pi}]}-\frac{E\left[(1-p(\pi))\left(q_{1} h+\xi y_{1}\right) \mid \pi \geq \hat{\pi}\right]}{E[p(\pi) \mid \pi \geq \hat{\pi}] l_{0}} \equiv 1+r^{*} .
\end{aligned}
$$

Given the offered rate $r_{0}=r^{*}$, an individual accepts the contract $\mathcal{C}$ if $V_{H}\left(\pi, r^{*}\right) \geq V_{R}(\pi)$. The cutoff type $\hat{\pi}$ is implicitly determined by:

$$
\begin{aligned}
V_{H}\left(\hat{\pi}, r^{*}\right) & =V_{R}(\hat{\pi}) \\
\Leftrightarrow \quad p(\hat{\pi}) & =\frac{E\left[u\left(c_{r}\left(y_{1}\right)\right)-u\left(c_{d}\left(y_{1}\right)\right) \mid \hat{\pi}\right]}{E\left[u\left(c_{n d}\left(y_{1}, q_{1}, r^{*}\right)\right)-u\left(c_{d}\left(y_{1}\right)\right)+(1-\chi) v(h) \mid \hat{\pi}\right]},
\end{aligned}
$$

where $c_{n d}, c_{d}$ and $c_{r}$ are given by equations (5), (4) and (8), respectively.

Proposition 2 The credit market equilibrium under asymmetric information is characterised by a pooling contract $\mathcal{C}=\left\{l_{0}, r^{*}\right\}$ and a cut-off type $\hat{\pi} \in[0,1]$ such that all individuals with $\pi \geq \hat{\pi}$ accept $\mathcal{C}$ and become home-owners, and all individuals with $\pi<\hat{\pi}$ become tenants, and the lenders break even in expectation on the whole pool of loans given $\hat{\pi}$.

Proof In Appendix A.1. 


\subsubsection{Discussion on the nature of the credit market equilibrium}

The pooling equilibrium described in this section rests on very strict assumptions. Three assumptions, in particular, are crucial: first, the fixed size of housing; second, the absence of consumption in the first period; and third, perfect competition in the credit market. The first two assumptions prevent any signaling by borrowers in the first period on their private types. The third one places a bound on the interest rates that a lender can offer. The assumption of equal initial endowments, on the other hand, could be relaxed to allow for idiosyncratic income also in the first period, as long as this income is not correlated with type (as in the second period). Because of these assumptions, lenders cannot infer anything about the loan applicants' types when offering the loan contracts, and pooling arises in equilibrium.

The pooling equilibrium also crucially depends on the set of available loan instruments and the incompleteness of markets. Here, I have assumed that only standard debt contracts are available. ${ }^{5}$ Then, under the assumptions above, no signaling by applying for loans for houses of different size or entailing different down payments is possible. But other types of contracts could allow for the separation of types in equilibrium.

The possibility of default offers partial consumption insurance if the individual is faced with adverse shocks, i.e. some state contingency. The absence of complete markets makes the loan contract lucrative for the subprime types. If lenders were allowed to offer state-contingent debt contracts, with higher interest rates but lower repayment ratios in case of adverse shocks, some types with a high income risk would find it optimal to self-select into these contracts.

Another possibility would be to allow for unsecured debt contracts. Then, a lender could offer contracts with a higher interest rate but no collateral alongside the collateralised debt contract. Again, this would offer better insurance for the lower types and could result in a separating equilibrium.

\footnotetext{
${ }^{5}$ De Meza and Webb (1999) argue that the standard debt contract can be optimal under certain conditions in a model of private types. In particular, assume that only the debt repayment is verifiable, and not the wealth of the borrower, when the debt is redeemed. However, in case of default, assume that also the borrower's wealth can be verified at no cost. Under such circumstances the standard debt contract is the optimal contract.
} 
Last, as noted for example by Tirole (2006, Ch. 6.5), it could be optimal for a lender to just pay the worst types to stay out of the market.

However, none of these features - state-contingent debt contracts, unsecured debt, or lenders offering to pay applicants in order not to apply are observed in actual credit markets for housing finance. I have chosen to make very strict assumptions in order to sustain a pooling equilibrium, because it offers a natural way to define overborrowing and subprime borrowers in a theoretical context. ${ }^{6}$

Finally, the assumption of perfectly competitive credit markets is crucial in sustaining the pooling equilibrium. Competition drives down the interest rate in such a way that no lender is able to deviate from the equilibrium by offering contracts with higher interest rates in an attempt to screen loan applicants. It is in essence the combination of private types and perfect competition that drives selection of subprime types in the market and creates the over-investment externality.

\section{Equilibrium and model solution}

\subsection{Timing}

The timing of the model is as follows. In every period $t$, a new generation enters. A generation indexed by its entry period $t=\tau$. Each generation lives for two periods, $t$ and $t+1$. The timing within the two periods of a generation entering in $t=0$ is outlined in Table 2 .

\subsection{Equilibrium and aggregation}

The equilibrium is an allocation $\left\{c_{t+1}^{\tau}, \hat{\pi}_{t}, h_{t}, r_{t}^{*}, q_{t}, s_{t}\right\}_{t=0}^{\infty}$ is such that given the interest rate $r_{t}^{*}$, the cut-off $\hat{\pi}_{t}$ satisfies (23) and the household consumption plan is given by $c_{t+1}^{\tau}=\left\{c^{n d}, c^{d}, c^{r}\right\}$, defined by equations (5), (4) and (8); the loan interest rate $r_{t}^{*}$ satisfies (22) given $\hat{\pi}_{t}$; the house sales price $q_{t}$

\footnotetext{
${ }^{6}$ I make no claim that the actual housing market in the U.S. during the housing boom would have been characterised by perfect pooling; however, some partial pooling of applicants seems likely to have been present.
} 
Period 0

- The generation $\tau=0$ is born and receives the first-period endowment $y_{0}$.

- The preceding generation $\tau=-1$ sells their housing stock to the real estate agents, consume, and exit.

- The new generation observes the house price $q_{0}$ and the income $y_{0}$, and make its housing choice. The cutoff type $\hat{\pi}_{0}$ is determined.

Period 1

- The house values $q_{1} \in q_{H}, q_{L}$ as well as the income realisations

$y_{1} \in y_{H}, y_{L}$ are realised and observed by all agents.

- The homeowners make their optimal default choice.

- The successful homeowners sell their housing to the real estate agents at the price $q_{1}$ and consume $c^{n d}\left(y_{1}, q_{1}\right)$.

- The renters consume $c^{r}\left(y_{1}\right)$ and the foreclosed homeowners consume $c^{d}\left(y_{1}\right)$.

- The generation $\tau=0$ exits while a new one enters.

Table 2: Timing of events

satisfies (10); the rental rate $s_{t}$ satisfies (11); and the following conditions hold:

$$
\begin{aligned}
Y^{\tau} & =C^{\tau}+H^{\tau} \\
\bar{h} & =\int_{0}^{1} h \mathrm{~d} \pi,
\end{aligned}
$$

where equation (24) is the aggregate consistency condition, and (25) is the housing market clearing condition; $\bar{h}$ denotes the aggregate housing stock, which is fixed. $C^{\tau}$ is the aggregate consumption of goods, $H^{\tau}$ is the aggregate consumption of housing services, and $Y^{\tau}$ is the aggregate income of generation $\tau$, born in period $\tau=t$. They are defined as:

$$
\begin{aligned}
C^{\tau} & =\int_{0}^{1} c_{t+1}^{\tau} \mathrm{d} \pi \\
H^{\tau} & =\int_{0}^{1} s_{t+1}^{\tau} \mathrm{d} \pi \\
Y^{\tau} & =\int_{0}^{\hat{\pi}_{\tau}}\left[(1+\bar{r}) y_{t}+y_{t+1}\right] \mathrm{d} \pi+\left(1-\gamma_{\tau}\right) \int_{\hat{\pi}_{\tau}}^{1}\left(y_{t+1}-\kappa\right) \mathrm{d} \pi \\
& +\gamma_{\tau} \int_{\hat{\pi}_{\tau}}^{1}\left[(1+r) y_{t}+y_{t+1}+\Delta q_{t+1}\right] \mathrm{d} \pi
\end{aligned}
$$


where $\hat{\pi}_{\tau}$ denotes the cutoff type in generation $\tau$, and $\gamma_{\tau}$ the ex-post fraction of non-defaulting home-owners in generation $\tau$ in the second period of their life. By the law of large numbers, $\gamma_{\tau} \rightarrow E[p(\pi) \mid \pi \geq \hat{\pi}]$.

\subsection{Functional forms}

I assume $\log$ utility $u(\cdot)=v(\cdot)=\log (\cdot)$ and a uniform distribution of types with $\pi \sim \operatorname{Uniform}(0,1)$. Under the latter assumption, $f(\pi)=1$ and $F(\pi)=\pi$ denote the p.d.f. and c.d.f. of $\pi$, respectively. These simple functional forms allow for an analytical solution of the equilibrium default probability and the equilibrium interest rate as well as a simple characterisation of the cut-off type.

In particular, the optimal default choice (12) is given by the condition:

$$
\begin{array}{r}
u\left(c_{d}\left(y_{1}\right)\right)+\chi v(h)>u\left(c_{n d}\left(y_{1}, q_{1}\right)\right)+v(h) \\
\Leftrightarrow \quad \log \left(c_{d}\left(y_{1}\right)\right)+\chi \log (h)>\log \left(c_{n d}\left(y_{1}, q_{1}\right)\right)+\log (h)
\end{array}
$$

By substituting in the budget constraints (4) and (3), this condition can be solved for:

$$
y_{1}+\Phi q_{1} h<\Phi\left(\left(1+r^{*}\right) l_{0}-\frac{\kappa}{h^{1-\chi}}\right)
$$

where $\Phi \equiv\left(1-\frac{1-\tau}{h^{1-\chi}}\right)^{-1}>0$.

Therefore, the ex-ante optimal default probability of a type $\pi$ is given by

$$
\operatorname{Pr}\left\{\text { 'default' }^{\prime} \pi\right\}=\operatorname{Pr}\left\{y_{1}+\Phi q_{1} h<\Phi\left(\left(1+r^{*}\right) l_{0}-\frac{\kappa}{h}\right) \mid \pi\right\} \equiv 1-p(\pi) \text {. }
$$

Then, the borrower optimally defaults if and only if the weighted sum of $y_{1}$ and $q_{1}$ realises a low enough value. In other words, default is optimal in the joint event of both $y_{1}$ and $q_{1}$ realising a low enough value. In the calibration I use, optimal default occurs only when $y_{1}=y_{L}$ and $q_{1}=q_{L}$, i.e. when the home-owner suffers both an adverse income and an adverse house value shock at the same time. In other states of the world, the borrower has no incentive to default.

In this case, the default probability of a type $\pi$ is $1-p(\pi)=(1-\phi)(1-$ $\pi)$, which is the joint probablity of the event $\left(y_{1}, q_{1}\right)=\left(y_{L}, q_{L}\right)$. 
Then the ex-ante default probability of a borrower from a lender's point of view, given the borrower cut-off type, is:

$$
\begin{aligned}
E[(1-\phi)(1-\pi) \mid \pi \geq \hat{\pi}] & =1-\phi-(1-\phi) E[\pi \mid \pi \geq \hat{\pi}] \\
& =1-\phi-(1-\phi) \frac{\int_{\hat{\pi}}^{1} \pi f(\pi) \mathrm{d} \pi}{1-F(\hat{\pi})} \\
& =\frac{1}{2}(1-\phi)(1-\hat{\pi}) .
\end{aligned}
$$

and correspondinly the no-default probability is $E[1-(1-\phi)(1-\pi) \mid \pi \geq$ $\hat{\pi}]=\frac{1}{2}(1+\phi+(1-\phi) \hat{\pi})$. Finally, the equilibrium pooling interest rate (22) in this case is:

$$
1+r^{*}=\frac{1+\bar{r}}{\frac{1}{2}(1+\phi+(1-\phi) \hat{\pi})}-\frac{1-\phi-(1-\phi) \hat{\pi}}{1+\phi+(1-\phi) \hat{\pi}} \frac{q_{L} h+\xi y_{L}}{l_{0}} .
$$

\subsection{Numerical calibration and solution}

The parameter values used in the numerical model solution and simulation are given in Table 3. They are chosen to mach some key housing market statistics from the U.S. data. The data moments are based on the figures given in Corbae and Quintin (2015) and on the author's own calculations based on the Case-Shiller index and the Survey of Consumer Finances.

Table 4 shows some statistics from the U.S. data and the corresponding statistics generated by the model under the calibration given in Table 3.

The data are annual and include data series on house prices, the homeownership rate, the mortgage delinquency rate and real income. The changes in house prices in the data are computed as the ratio of the CaseShiller national house prices index to its trend in 2006 (the peak-to-trend ratio) and in 2012 (the trough-to-trend) ratio in the sample 1991-2015. The homeownership rate is the U.S. average over the sample period 1991-2015. The delinquency rate is the average delinquency rate on all single-family residential mortgages over the same sample period. Real personal income growth is measured as the overall growth over 1975-2015. The model matches all of these long-run averages quite well. 


\begin{tabular}{lc} 
Parameter & Value \\
\hline Safe interest rate $\bar{R}$ & 1.04 \\
Utility from owner-occ. $\mathrm{h} v_{H}(h)$ & 0.2 \\
Lender appropriation rate $\tilde{\xi}$ & 0.288 \\
High house value prob. $\phi$ & 0.915 \\
Default DWL cost $\kappa$ & 2.08 \\
$q_{0} / y_{0}$ & 2.94 \\
$q_{H} / q_{0}$ & 1.07 \\
$q_{L} / q_{0}$ & 0.24 \\
$y_{H} / y_{0}$ & 1.43 \\
$y_{L} / y_{0}$ & 0.71
\end{tabular}

Table 3: Baseline parameter calibration

According to Ospina and Uhlig (2016), the average loan-to-value ratio at origination over 2006-2012 was 0.7. Hayre and Saraf (2008) estimate that losses in the event of default range from $35 \%$ to $60 \%$. I choose parameter values that produce a recovery rate of 0.48 , which is well in the range of these estimates and also consistent with the value used in Corbae and Quintin (2015). Also in line with the results in Corbae and Quintin (2015), I choose parameters such that default is optimal only when hit by both adverse shocks. Finally, based on figures reported in Kawano and LaLumia (2015), annual income loss at unemployment is at around $76 \%$ in the data. I choose the income parameters to roughly replicate this figure.

The spread between 30-year fixed rate mortgages and the 30-year T-bond has been on average 162bp over the sample 1977-2002, before the financial crisis and the boom. The model is consistent with this figure. Household indebtedness, measured as the ratio of total household debt to disposable income, was around $130 \%$ at the peak of the boom in 2006 . The model produces a ratio somewhat higher than this peak observed in the data. Finally, data on household consumption expenditures shows a share of around $40 \%$ going towards rents, whereas the model produces a somewhat lower figure.

In order to study the behaviour of the model, I solve for the equilibrium numerically using iteration methods. The numerical solution algorithm is described in Appendix A.2. Taken together, the figures in Tables 3 and 4 show that the model, while simple, can replicate some of the long-run averages in the U.S. housing market data. In the next section, I look at some comparative statistics to gauge further how the selection into homeownership depends especially on the safe interest rate $\bar{r}$ and on the housing 


\begin{tabular}{lcc} 
Variable & Data & Model \\
\hline Safe interest rate & 1.04 & 1.04 \\
Homeownership rate & 0.66 & 0.66 \\
Average recovery rate & 0.5 & 0.48 \\
Delinquency rate & 0.023 & 0.028 \\
Loan-to-value ratio & 0.7 & 0.66 \\
House prices peak-to-trend & 1.33 & 1.07 \\
House prices trough-to-trend & 0.83 & 0.24 \\
Real personal inc. 1975-2015 & 1.33 & 1.43 \\
Income loss at unempl. & 0.76 & 0.71 \\
Loan spread & $162 \mathrm{bp}$ & $162 \mathrm{bp}$ \\
Household indebtedness ratio & 1.30 & 1.94 \\
Rent-to-income ratio & 0.38 & 0.20 \\
Default only when $\left(y_{L}, q_{L}\right)$ & $\checkmark$ & $\checkmark$
\end{tabular}

Table 4: Data moments and model counterparts

value risk $\phi$.

\section{$5 \quad$ Equilibrium characteristics}

In this section, I describe some equilibrium features of the model: overinvestment in housing, the source of this inefficiency, and the links between default rates, house prices, and interest rates.

\subsection{The over-investment externality and subprime borrowing}

The key feature of models of the credit market with a De Meza and Webb (1987) type of information structure, such as here, is that the equilibrium in the credit market equilibrium is inefficient in the sense that there is over-investment compared to the first best whenever there is a non-zero possibility of borrower default.

The marginal type $\hat{\pi}$ is the riskiest type in the loan pool, meaning that the loan pool is riskier than it would be under symmetric information. Equivalently, as the pooling interest rate $r^{*}$ is decreasing in $\hat{\pi}$, this implies that $\hat{\pi} \leq \hat{\pi}^{F B}$ for all $\hat{\pi}$. The set of borrowers of borrowers that are able to get a loan under asymmetric information, but would not do so under symmetric information can be called subprime borrowers. They are borrowers whose loans are not socially optimal. In particular, under the assumption of uniform distribution of types, this set is equal to the share $\hat{\pi}^{F B}-\hat{\pi}$. 


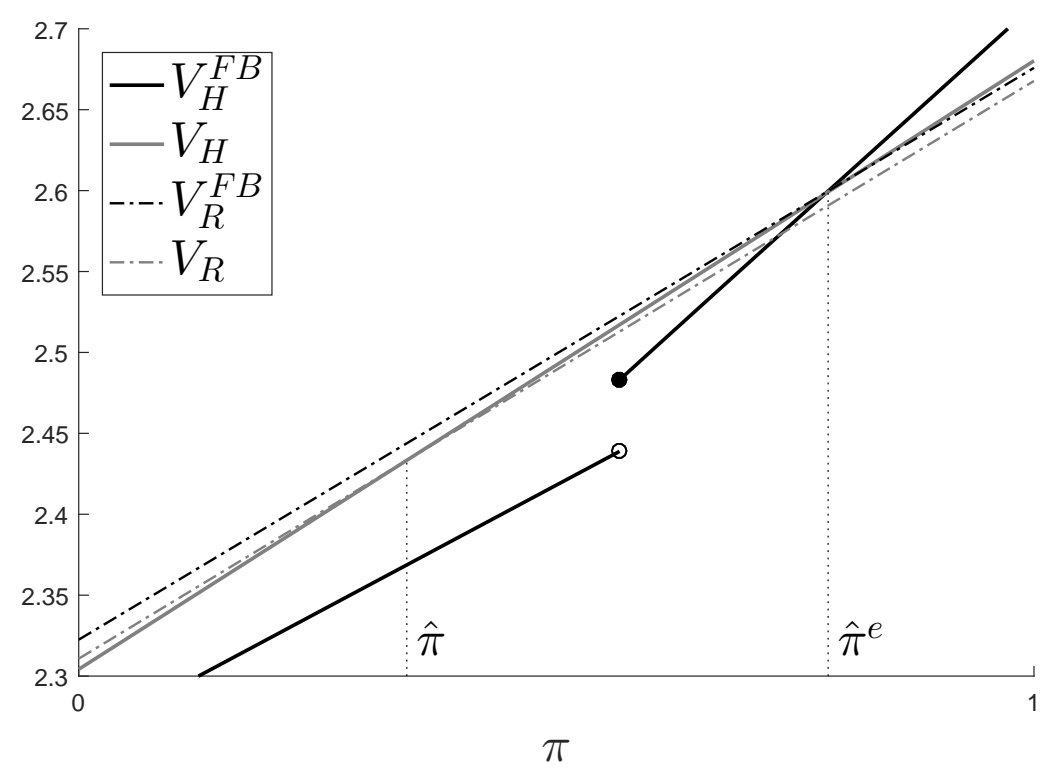

Figure 2: Value functions under symmetric and asymmetric information

Similarly, under uniformly distributed types, the homeownership rate is defined as $1-\hat{\pi}$.

This is illustrated in Figure 2, which shows the value functions of a tenant $V_{R}(\pi)$ and a home-owner $V_{H}(\pi)$ as a function of type $\pi$, together with their respective first-best counterparts. All value functions are increasing in the type: a high type has, on expectation, a higher consumption in the second period because of the lower income risk.

Two notable features of the equilibrium are shown in the figure. First, there is a discontinuity in the homeowner's value function under symmetric information, $V_{H}^{F B}(\pi)$. This is because the lowest types, left of the jump, default whenever they face the low house value shock $q_{1}=q_{L}$, regardless of their income $y_{1}$. This high default probability is reflected in a very high interest rate offered to them, which makes borrowing very expensive for them.

This discontinuity is absent in the corresponding value function under asymmetric information, $V_{H}(\pi)$. This reflects the externality associated with entry into the credit market. If an agent of type $\pi$ enters the market and takes a loan, it yields her an expected marginal utility of consumption 
$u^{\prime}\left(c_{n d}\right)$ with probability of $p(\pi)$, i.e. if she does not default. This expectation is the higher, the higher the type. The cost of entry, however, does not depend on type: the pooling interest rate $1+r^{*}$ is the same for all entrants. The asymmetric information case is parametrised here in such a way that default is only optimal when $\left(y_{1}, q_{1}\right)=\left(y_{L}, q_{L}\right)$.

However, by entering the market, the marginal borrower makes the pool marginally riskier, and thus increases the interest rate faced by all other agents in the credit market as well. It is this change in the interest rate $r^{*}$ induced by entry, which affects the consumption available in the nodefault state for every borrower, that the marginal borrower does not internalise under asymmetric information. In the symmetric case, the interest rate $1+r(\pi)$ correctly reflects each type's riskiness, so that the externality disappears.

The second important feature is that the value functions $V_{H}(\pi)$ and $V_{H}^{F B}(\pi)$ cross exactly at the efficient cut-off $\hat{\pi}^{F B}$. This reflects the cross-subsidisation induced by credit market pooling. All types $\pi>\hat{\pi}^{F B}$ would better off under symmetric information, because they would face cheaper interest rates than the pooling rate. Conversely, all types $\hat{\pi}^{F B} \geq \pi \geq \hat{\pi}$ are better off under asymmetric information: they are being subsidised by the types $\pi>\hat{\pi}^{F B}$ and enjoy a lower interest rate than they would under symmetric information. They are also types that would not enter the credit market under symmetric information.

The implications of an increase in credit supply, i.e. a decrease in the cut-off $\hat{\pi}$, on aggregate consumption are more subtle. There are two effects that move in different directions. As more households gain access to the credit market and can consume capital gains on their housing, aggregate consumption increases. But as the borrower pool expands, it also becomes riskier, so the interest rate on loans rises. This increases the user cost of housing, which includes the interest payments on the loan. This mechanically increases the value of consumption of housing services, but reduces resources left for the consumption of goods other than housing services. The aggregate effect depends on which component dominates, but for plausible parameter values, it is positive when house prices are increasing. Conversely, when house prices decline, capital gains are eroded, which contracts aggregate consumption. 

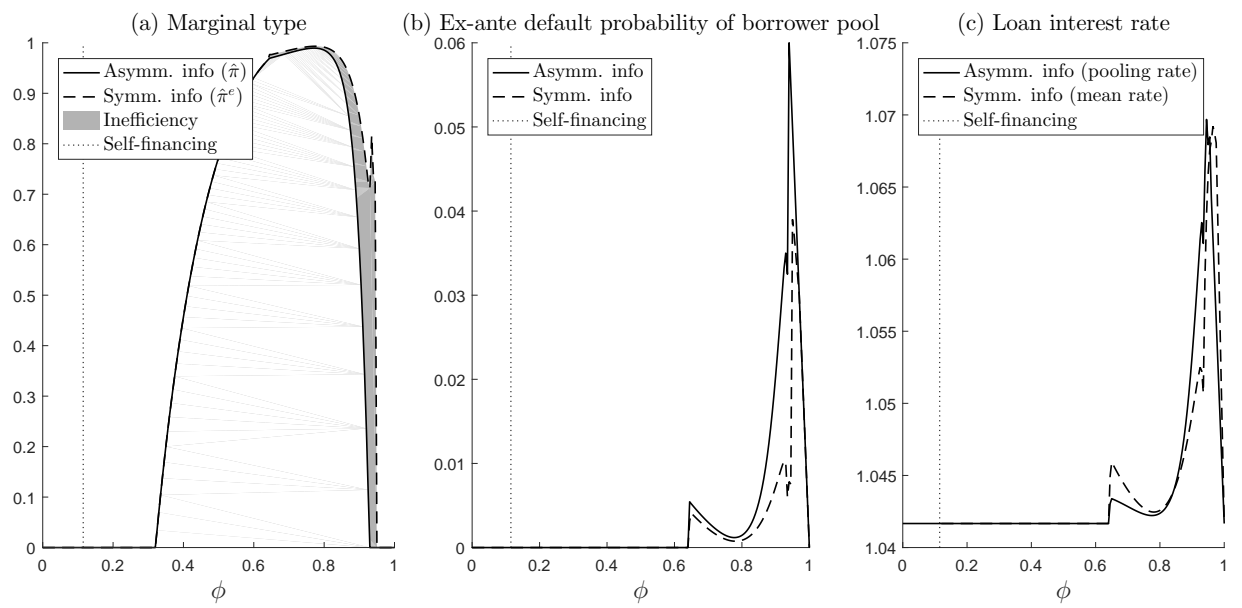

Figure 3: Equilibrium cut-off types and default probability of the borrower pool as a function of the house price risk $\phi$

\subsection{Comparative statics}

To gauge how the the overborrowing externality depends on the various parameters of the model, I perform a comparative statistics where I change three key parameters of the model one-by-one, all the while keeping all other parameters fixed. The parameters of interest are the probability of a high house value realisation $\phi$, the safe interest rate $1+\bar{r}$, and the lender appropriation rate $\xi$.

The extent of the externality is quantified in Figures 3 and 4, and 4. They show how the marginal type $\hat{\pi}$, the ex-ante default probability of default in the borrower pool observed by the lender, $E[1-p(\pi) \mid \pi \geq \hat{\pi}]$, and the equilibrium pooling loan interest rate $r^{*}$ (or the mean equilibrium interest rate under symmetric information, defined as $\left.\int_{\hat{\pi}^{F B}}^{1} r(\pi) \mathrm{d} \pi\right)$ change as three key parameters of the models change.

As Figure 3 shows, the model exhibits a non-linear relationship between the probability of a high house value realisation $\phi$ and demand for owneroccupied housing, i.e. the marginal type, all other parameter being fixed at their benchmark values. Strikingly, the homeownership rate is $100 \%$ (i.e. the marginal type is 0 ) both when a high house value is very unlikely and very likely. 
At the limit, when the high house value $y_{H}$ will never occur, i.e. when $\phi=0$, the purchase price of the house is equal to the low value: $q_{0}=q_{L}$. Then, buying a house is very cheap, and there is no price risk involved. As a consequence, owning is very attractive to all types, even those with low expected income. Even as $\phi$ becomes positive, for low values, $q_{0}=$ $\phi q_{H}+(1-\phi) q_{L}$ remains low. Because loan amounts are low and homeowners derive a utility bonus from owning rather than renting, default is never optimal for any type $\pi$ when $\phi$ is low. The threshold under which households are able to self-finance is marked in the left panel of Figure 3 by a vertical dashed line.

As $\phi$ increases, also the purchase price $q_{0}$ and loan amounts increase. At first, the worst types who have the lowest expected income start opting out and renting instead. However, default remains non-optimal for all types in the borrower pool. Eventually, as $q_{0}$ keeps rising, default becomes optimal for some types. There is a discontinuous jump of the ex-ante default probability of the borrower pool away from zero at around $\phi=0.63$. At this point, as defaults become a non-zero probability event, the overinvestment externality kicks in and the asymmetric information equilibrium is no longer efficient: the efficient marginal type is higher than the actual one under asymmetric information.

As the probality of the high house value and therefore the purchase price $q_{0}$ keep rising, the worst types keep opting out of the credit market, and thus the borrower pool becomes safer. Although defaults still happen, the pool becomes less risky.

However, as the high house value becomes likely enough, at around $\phi=$ 0.80 , riskier types with worse income expectations are drawn back to the credit market. Consequently, the ex-ante default rate sharply increases, peaking at $\phi=0.95$.

The loan interest rates depend on the default probabilities and thus largely follow the changes in default incentives. The mean loan interest rate under symmetric information is higher than the pooling loan rate under asymmetric information in certain regions. This reflects the fact that under symmetric information, each type is charged a rate that reflects their true ex-ante default probability. 

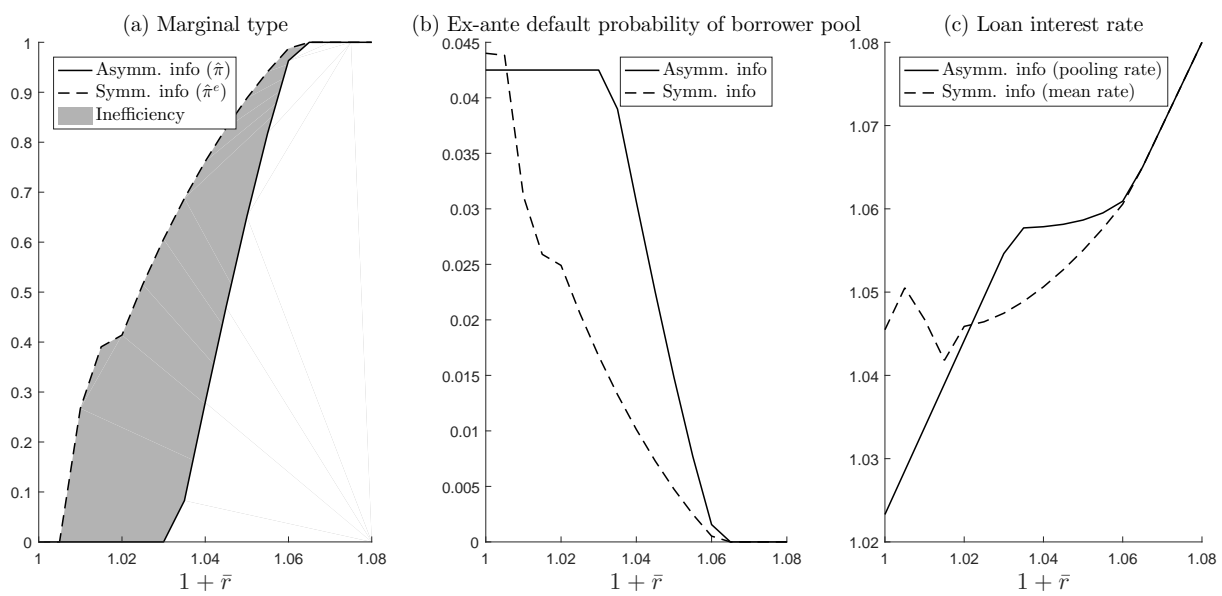

Figure 4: Equilibrium cut-off types and default probability of the borrower pool as a function of the outside interest rate $1+\bar{r}$

For very high values of $\phi$ in the range $0.95-0.99$, homeowners actually default whenever they are hit by a low house value also under asymmetric information, regardless of their income realisation, because they are so highly levered. Then the ex-ante default probability is no longer dependent of the composition of the borrower pool. In this region, the inefficiency thus disappears. This behaviour is ruled out in the benchmark calibration, where $\phi=0.915$. The kink in the default probability of the borrower pool under symmetric information in the figure also reflects these discontinuities in default incentives.

It is in this region of increasing market participation that the over-investment inefficiency is at its worst. For a given value of $\phi$, the vertical distance of the two curves measures the extent of this inefficiency, or the amount of subprime borrowing. Then this distance can also be interpreted to measure the looseness of lending standards relative to first-best: it shows that lending standards are loose exactly when high house values are relatively likely.

Figure 4 shows a similar exercise of comparative statics for the interest rate $1+\bar{r}$, all other parameter being fixed at their benchmark values. The baseline value is $1+\bar{r}=1.044$.

The marginal type is increasing in the safe interest rate. When $\bar{r}$ is low, 

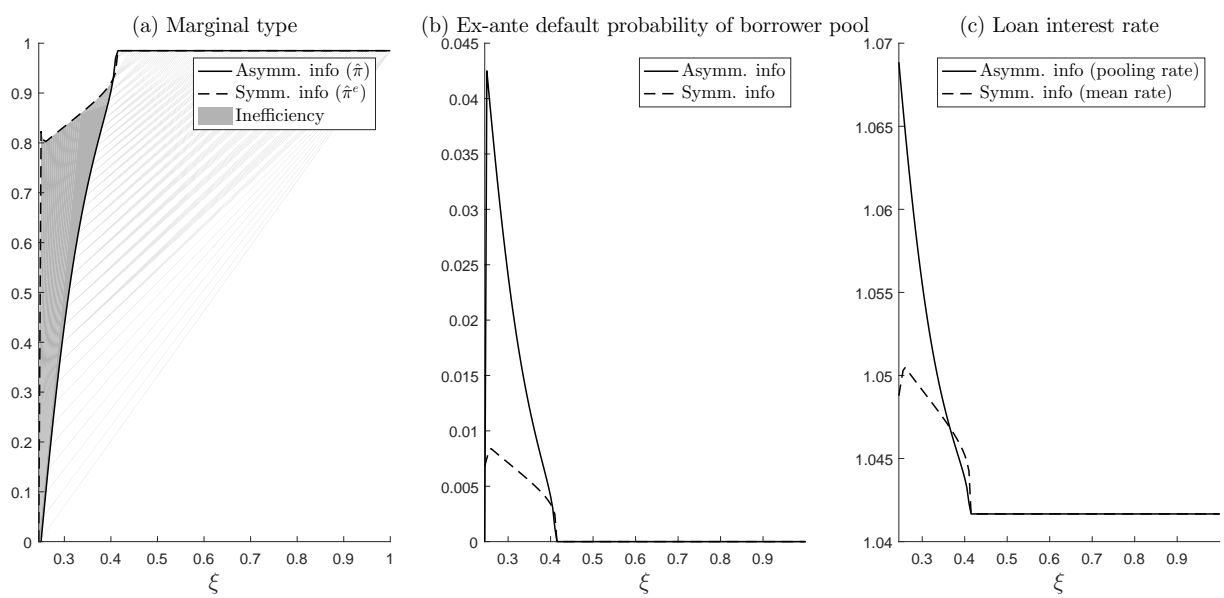

Figure 5: Equilibrium cut-off types and default probabilities of the borrower pool as a function of the lender appropriation rate $\xi$

the cost of lending as well as the outside return for savings is low as well. Therefore purchasing a house is very attractive. As the safe interest rate increases, borrowing becomes more expensive and the outside return better; this leads the worst types to opt out of the credit market. The inefficiency is worst at low values of $\bar{r}$ : since in the symmetric information economy each agent's cost of funding reflects their true riskiness as borrowers through a type-dependent margin over the safe rate, it increases faster for low types than when they face the pooling interest rate. These marginal types then choose to opt out for lower values of $\bar{r}$ than under asymmetric information.

The average ex-ante default probability of the borrower pool is higher under symmetric than asymmetric information when $\bar{r}$ is very low (notably, when $\bar{r}<1.01$ ). This is because when borrowing is very cheap and thus attractive, some households default whenever $q_{1}=q_{L}$, regardless of their income realisation $y_{1}$. The lenders know this and charge appropriately high interest rates to cover this higher default probability.

As the borrowing rates are pinned down by the safe interest rate $\bar{r}$, they increase as $\bar{r}$ increases. Here, for a low safe interest rate level, the mean loan rate under symmetric information is notable higher than the pooling rate under asymmetric information. In this region, participation is also very high. This suggests that the subsidisation of high-risk borrowers is 
particularly strong, which is reflected also in the large inefficiency region in Panel (a) of the figure.

Finally, Figure 5 shows a comparative statics exercise with respect to the lender appropriation rate $\xi$. The rest of the parameters are calibrated as in the benchmark case summarised in Table 3. Recall that when $\xi=0$, the lender cannot seize any of the second-period income of the borrower in case of default, and when $\xi=1$, she can seize all of it, in addition to the house. The baseline value is $\xi=0.288$. For values below $\xi=0.25$, no equilibrium exists given the rest of the parameter values in the benchmark calibration; thus only the range $\xi \in[0.25,1]$ is reported in the figure.

This exercise shows that stricter regulation in case of default - as $\xi$ increases - mitigates incentives for default. At around $\xi=0.45$, no households wants to take out a loan and risk losing such a share of their income in case of default. Consequently, also the default rate declines. But this also mean that the default regulation is so strict that homeownership goes down to zero. Such a regulation is a much too blunt tool to curb the overborrowing problem: it affects all borrowers equally. A policy that aims to curb the overborrowing externality needs to address the borrowing incentives directly.

\subsubsection{Discussion}

The characteristics of the equilibrium described in this section have some poignant policy implications.

The comparative statistics exercises highlight that the over-investment externality is particularly big first, when house values are relatively high on expectation, which is reflected in high purchase prices; and second, when interest rates are relatively low. These are exactly the type of conditions that prevailed in the U.S. during the housing boom.

First, there is a direct link between the over-investment externality and the conduct of monetary policy. A low interest rate regime directly fuels households' incentives to take on debt, which is not suprising. Notably, the effective Federal Funds rate was very low, around 1\%, in 2002-2003 at 
the height of the housing boom. ${ }^{7}$

Second, the cross-subsidisation of high-risk borrowers is at the heart of the externality. In the U.S. and many other countries, promoting homeownership by supporting cheap and accessible mortgage borrowing has been a political priority for decades. This has likely made borrowing too cheap for many households.

Finally, during the housing boom years of the early 2000s, it was not uncommon for lenders to offer very low "teaser rates" for on new adjustablerate loans, further increasing the attractiveness of these loans in the eyes of many households. When the interest rates on these loans increased after the teaser period, many borrowers found themselves unable to service their debt. This suggests that they would not, or perhaps should not, have borrowed on terms that truly reflected their credit risk.

These observations demonstrate that there are very important links between monetary policy and financial stability stemming from the links between interest rates and the incentives for borrowing and defaulting among borrowers.

\section{An endogenous boom-bust cycle}

So far, the model I have presented is essentially static in nature. Because there is no aggregate uncertainty, the expected value of housing is the same for each entering generation, and there are no aggregate cycles. The problem of each generation is identical to any other.

In this section, I extend the model to allow for an endogenous boom-bust cycle in house prices. Two additional ingredients are needed. The first one is an aggregate demand complementarity in housing: the households must derive more utility from owning a house when many others own a house as well. This element captures the "boom" in the house price cycle: it can be interpreted as a sort of hype surrounding homeownership that induces more households to enter the housing market.

\footnotetext{
${ }^{7}$ See e.g. the data published at https://fred.stlouisfed.org/series/FEDFUNDS for the evolution of the effective Federal Funds rate.
} 
The second ingredient is a deadweight cost of default on the price of foreclosed housing. So far, the only deadweight cost in the model $(\kappa)$ is incurred on the income of the defaulting household. This is an idiosyncratic cost that the defaulting household alone bears, and it is included only to prevent default from being too attractive to an individual borrower. It can be thought of capturing for example legal costs, loss of access to the credit market after default, or loss of reputation after default.

On top of this idiosyncratic deadweight cost, I now impose a cost of default on the aggregate housing stock, which depends on the aggregate default rate in the economy. It can be thought of capturing the fact that foreclosed housing often sells at a big discount relative to market prices, reflecting a pecuniary externality of default on housing. This element captures the "bust" in the house price cycle.

\subsection{The aggregate demand complementarity}

I modify the value function of a homeowner by adding an aggregate demand complementarity that depends on the aggregate homeownership rate $1-\hat{\pi}^{8}$ Specifically, the value function is now:

$$
\begin{aligned}
V_{H}(\pi ; \hat{\pi})= & E\left[u\left(c_{1}\left(y_{1}, q_{1}\right)\right)+v(h)+g(1-\hat{\pi}) \mid \pi\right] \\
= & p(\pi) E\left[u\left(c_{n d}\left(y_{1}, q_{1}\right)\right)+v(h)+g(1-\hat{\pi}) \mid \pi\right]+ \\
& (1-p(\pi)) E\left[u\left(c_{d}\left(y_{1}\right)\right)+\chi v(h) \mid \pi\right]
\end{aligned}
$$

In this formulation, $g:[0,1] \rightarrow \mathbb{R}$ is a strictly strictly increasing function of the homeownership rate $1-\hat{\pi}$ with a slope $0<g^{\prime}(1-\hat{\pi})<1 \quad \forall \hat{\pi}$. This implies a weak demand complementarity in homeownership. A slope above one would imple a strong complementarity, which opens up the possibility of equilibrium multiplicity. Beaudry et al. (2015) show that a slope of the demand complementarity function below unity guarantees a unique equilibrium, but can accommodate a deterministic cycle around this equilibrium.

\footnotetext{
${ }^{8}$ This definition of the homeownership rate hinges on the continued assumption of uniformly distributed types.
} 
A further assumption is that a tenant does not enjoy this demand complementarity. A tenant's value function is thus unchanged from the baseline formulation (6), reproduced here for convenience:

$$
V_{R}(\pi)=E\left[u\left(c_{r}\left(y_{1}\right)\right)+\chi v(h) \mid \pi\right]
$$

The household's value function is then:

$$
V(\pi ; \hat{\pi})=\max \left\{V_{H}(\pi ; \hat{\pi}), V_{R}(\pi)\right\}
$$

In the numerical computations, I use the functional form

$$
g(1-\hat{\pi})=\alpha \log (1+(1-\hat{\pi}))
$$

where $\alpha>0$ is a parameter that governs the strength of the complementarity. When $\hat{\pi}=1$, i.e. the homeownership rate is zero, the demand complementarity equals zero as well. At the other extreme, when $\hat{\pi}=0, g$ attains a maximum at $\alpha \log (2)$. Setting $0<\alpha<1$ guarantees that $0<g^{\prime}(\cdot)<1$ everywhere in the interval $[0,1]$.

The ex-post default choice and the ex-ante no-default probability $p(\pi ; \hat{\pi})$ are modified accordingly and now also depend on the aggregate home ownership rate. A borrower of type $\pi$ defaults in the second period if and only if:

$$
u\left(c_{d}\left(y_{1}\right)\right)+\chi v(h)>u\left(c_{n d}\left(y_{1}, q_{1}\right)\right)+v(h)+g(1-\hat{\pi}) .
$$

\subsection{The cost of default}

The second extension to the baseline model is the inclusion of a deadweight cost of default on the house price. I now assume that each housing unit seized and sold by the lender after a default suffers a cost $1-\psi$ proportional to the market price $q_{1}$, with $0<\psi<1$. That is, a house $h$ that is foreclosed only yields $\psi q_{1} h$ to the lender who sells it to a real estate agent, and the real estate agent also receives $\psi q_{1} h$. The share $(1-\psi) q_{1} h$ is lost. It represents a pecuniary externality - a haircut - on the share of the aggregate housing stock that is foreclosed. 


\begin{tabular}{lclcc} 
Parameter & Value & Target & Baseline & Boom-bust \\
\hline Demand complementarity $\alpha$ & 0.99 & - & - & - \\
DWL cost on housing $\psi$ & 0.5 & - & 1.04 & 1.04 \\
Safe interest rate $\bar{R}$ & 1.04 & Safe interest rate & 0.66 & 0.80 \\
Utility from owner-occ. $\mathrm{h} v_{H}(h)$ & 0.12 & Homeownership rate & 0.5 & 0.3 \\
Lender appropriation rate $\bar{\xi}$ & 0.3 & Average recovery rate & 0.03 & 0.034 \\
High house value prob. $\phi$ & 0.915 & Delinquency rate & $\checkmark$ & $\checkmark$ \\
Default DWL cost $\kappa$ & 2.11 & Default only when $\left(y_{L}, q_{L}\right)$ & 0.66 & 0.66 \\
$q_{0} / y_{0}$ & 2.94 & Loan-to-value ratio & 1.07 & 1.07 \\
$q_{H} / q_{0}$ & 1.07 & Peak-to-trend & 0.24 & 0.24 \\
$q_{L} / q_{0}$ & 0.24 & Trough-to-trend & 1.43 & 1.43 \\
$y_{H} / y_{0}$ & 1.43 & Relative income growth & 0.71 & 0.71 \\
$y_{L} / y_{0}$ & 0.71 & Relative income loss &
\end{tabular}

Table 5: Boom-bust parameter calibration. "Baseline" refers to the targeted equilibrium values under the baseline calibration, replicated from Table 3. "Boom-bust" refers to the equilibrium values under the boom-bust calibration, around which the system oscillates.

A homeowner who does not default on his loan is not subject to this cost, and is able to sell his house at the market price $q_{1} h$.

Denote by $\mathcal{S}$ the set of possible states of the world $\left(y_{1}, q_{1}\right)$ and by $S$ the number of different states $\mathcal{S}$. In particular, we have $\mathcal{S}=\left\{\left(y_{H}, q_{H}\right),\left(y_{L}, q_{H}\right)\right.$, $\left.\left(y_{H}, q_{L}\right),\left(y_{L}, q_{L}\right)\right\}$ and $S=4$.

The value of the aggregate stock of housing of an exiting generation, $\bar{q}$, is then:

$$
\bar{q}=f(\bar{\pi}, \phi)\left(\mathbb{I}-\mathbb{1}_{n d}\right) \mathbf{q}+f(\bar{\pi}, \phi) \mathbb{1}_{n d} \psi \mathbf{q}
$$

where $\mathbb{1}_{n d}$ in a $S \times S$ diagonal matrix with elements $i_{s s}=1$ if there is default in state $s$ and $i_{s s}=0$ if there is not.

Furthermore, $f(\bar{\pi}, \phi)=\left[\begin{array}{llll}\bar{\pi} \phi & (1-\bar{\pi}) \phi & \bar{\pi}(1-\phi) & (1-\bar{\pi})(1-\phi)\end{array}\right](1 \times$ $S)$ is the joint distribution of the average income shock type $\pi$ on the market and the house value shock $\phi$, where $\bar{\pi} \equiv E[\pi \mid \pi \geq \hat{\pi}]=\frac{1+\hat{\pi}}{2}$. Finally, $\mathbf{q}=\left[\begin{array}{ll}\mathbf{q}_{\mathbf{H}} & \mathbf{q}_{\mathbf{L}}\end{array}\right]^{\prime}$ is a $S \times 1$ vector of house values.

This expression picks up the states in which default happens and discounts the house values by $\psi$ in those states, while the values remain unaffected in the no-default states. It then computes the expected value of the housing stock, which equals the ex-post average value of the stock under the law of large numbers. 
(a) Model

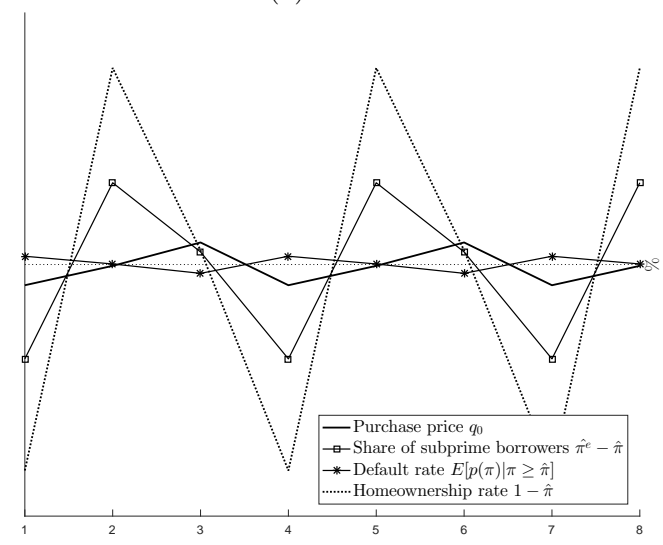

(b) Data

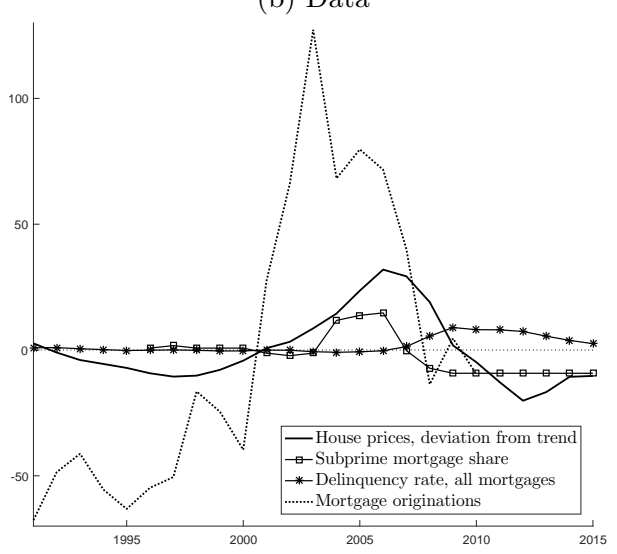

Figure 6: Boom-bust model dynamics and the data. Panel (a): Model dynamics, deviations from mean. Panel (b): Data, percentage deviations from mean or trend.

\subsection{Parametrisation of the extended model}

The behaviour of the model and the dynamics of the house price cycle are very sensitive to the parameter values. The length, magnitude and frequency of the deterministic cycle can vary significantly.

I do not attempt to make any quantitative claims on the nature and dynamics of house price cycles. Instead, I show below a specific example that demonstrates that the model can, qualitatively, replicate a similar pattern in house prices, default rate, and homeownership rate as observed in the data in Figure 1.

The parametrisation mostly follows the baseline presented in Table 3 in Section 4.4. The demand complementarity parameter $\alpha$ and the haircut on house values $\psi$ govern the behaviour on the cycle, and are chosen to qualitatively match the cyclical patterns observed in Figure 1. The demand complementarity strengthens the incentives for buying a house. The utility from homeownership $v_{H}(h)$, the deadweight cost of default $\kappa$, and the lender appropriation rate $\xi$ are adjusted to dampen incentive to enter the housing market, in order to mitigate the effect on the homeownership rate. 


\subsection{Boom-bust dynamics}

This section presents and discusses the dynamics of the model under the parametrisation in Table 5, and compares these dynamics to the patterns observed in data.

Panel (a) of Figure 6 plots the dynamics of the extended model. The model exhibits a deterministic cycle of three periods around its equilibrium. All variables are expressed in deviations from their mean values. Panel (b) replicates the data from Figure 1; here, for ease of comparison with the model counterparts, all series are either de-meaned or de-trended by removing a linear trend.

The model dynamics work as follows. Imagine, first, a situation where the purchase price of housing $q_{0}$ and the homeownership rate $1-\hat{\pi}$ both are low. This implies, at the same time, that the share of subprime borrowers is low.

In the next period, cheap housing the attracts more buyers on the market. In addition, because there were initially few subprime borrowers in the market to start with, the default rate is low, and defaults do not impose large discounts on house sales. Thus, the purchase price of housing increases. At the same time, as homeownership is more attractive, the share of subprime borrowers also increases.

In the next phase, because the average quality of borrowers deteriorated, defaults start to go up, house prices are depressed, and homeownership becomes less attractive. Subsequently, the cycle starts again from a state of low house prices and low homeownership.

Qualitatively, the model matches the patterns observed in data remarkably well. In particular, in the data, house prices peak in 2006. New mortgage originations peak slightly earlier, in 2003, and remain elevated through 2006. Likewise, the share of subprime borrowing remains stable until 2003, increases in 2004 and remains high during the mortgage boom in 20042006, after which it collapses. The delinquency rate only picks up later: in the data, this happens in 2009.

The model exhibits these same patterns. When house prices are rising, homeownership increases; in the context of the model, this translates di- 


\begin{tabular}{lcc} 
Ratio of standard errors & Data & Model \\
\hline Loan originations to house prices & 5.2 & 9.4 \\
Subprime loan originations to all loan originations & 0.02 & 0.44 \\
Default rate to loan originations & 0.045 & 0.042 \\
Default rate to house prices & 0.23 & 0.40
\end{tabular}

Table 6: Relative volatilities of the series in Figure 6. Note: measured as the ratio of standard errors. "Model": series in Panel (a), "Data": series in Panel (b) of Figure 6, respectively.

rectly into new loan originations. At the same time, the share of subprime borrowers increases, as less creditworthy households are attracted into the credit market. Homeownership peaks earlier than house prices. Finally, as in the data, there is a lag between the peak in house prices and the peak in defaults.

In terms of relative magnitudes, the model also performs very well. The relative volatilities of the series in Figure 6 are presented in Table 6. All, expect the volatility of subprime loans to all loans, are of the same order of magnitude in both the data and the model.

Most notably, new loan originations are more volatile than house prices. In the model, there are only two assets available to the household (the safe deposit and the risky investment in housing), and moreover, the diversification of endowments into both assets is not optimal. Therefore small changes in the price of the risky assets induce large fluctuations in the households' investment incentives, and consequently, the homeownership rate as well as the share of subprime borrowers. On the other hand, as only a small fraction of borrowers default in any given period, only a small fraction of the housing stock is subject to a haircut. There is no asset price bubble or over-heating of the market that would lead to large swings in house prices.

In the data, the changes in the homeownership rate are small (not depicted in the figure here), but the volume of new residential mortgage loan originations grows 7 -fold in absolute terms, or from $70 \%$ below mean to $120 \%$ above mean over the boom period. This amount includes also refinancing and home equity loans, not only loans for new purchases, which are strictly speaking absent in the model. Nonetheless, mortgages for new 
purchases amount to a substantial share of total mortgage originations. ${ }^{9}$

It has to be noted, however, that the fluctuations in the theoretical model are very small in magnitude in absolute terms: they are weak oscillations around the model equilibrium, much smaller in absolute magnitude than the cycles observed in the data. The model is not intended to be a quantitative model of business or house price cycles; in order to work as such, it would need more powerful mechanisms that induce aggregate fluctuations. Here, all uncertainty is still idiosyncratic, and the fluctuations are created by externalities stemming from the demand complementarity on the one hand, and the default discount on the other hand. ${ }^{10}$

\section{Conclusions}

This papers outlines a model of the housing market where housing finance is affected by an adverse selection problem. The selection is towards less creditworthy borrowers, which implies equilibrium overborrowing with respect to the first-best. Overborrowing must then be understood as a macroeconomic problem, not an individual-level one: each household chooses optimally to take on debt, and lenders choose optimally their loan offers, but the market failure caused by hidden borrower types can lead to too much debt in aggregate from a social point of view.

The first goal of this paper is to shed light on the micro-level mechanisms and incentives that can cause equilibrium over-investment and endogenous fluctuations in lending standards, captured by the endogenous share of subprime borrowers in the market.

The second goal is to demonstrate how a combination of private information, aggregate demand complementarities and deadweight costs of default can create endogenous cycles in the housing market. These dynamics can help understand which factors contribute to the creation of boom-bust cycles in housing markets.

\footnotetext{
${ }^{9}$ See e.g. the Mortgage Bankers Association (2016) for more detailed information on mortgage origination by purpose.

${ }^{10}$ I have left out the scale of the $y$-axis in Panel (a) of Figure 6 in order to highlight the qualitative patterns in the cycles generated by the model and observed in the data.
} 
The model, while simple, succeeds in replicating some key statistics of long-run averages in the U.S. housing market before the subprime crisis, such as the default rate, homeownership rate, and loan-to-income ratio.

The extended version of the model also captures qualitatively, in terms of relative volatilities as well as in terms of timing of the credit and house price cycles, the patterns observed in the U.S. data in 1990-2015. This time period includes both the run-up to the subprime crisis, the peak of the housing boom, and the subsequent collapse of the housing market.

Using comparative statics, I show that lending standards are loose and there is a lot of overborrowing first, when future house values are expected to be high, which leads to high purchase prices of housing; and second, when safe interest rates are relatively low, which implies low costs of borrowing as well as a low opportunity cost on housing investment. In these circumstances, the incentives of not-very-creditworthy borrowers to enter the credit market are the strongest: their outside returns are low, expected capital gains on housing are high, and the cost of borrowing is low. These are also the conditions which correlate with the greatest inefficiency in the credit market, or in other words, with very loose lending standards.

These are exactly the circumstances which prevailed in the U.S. prior to the subprime crisis in the early 2000s; the results are consistent with a substantial market failure in housing finance in the years prior to the crisis. They also demonstrate that there are strong and important links between the conduct of monetary policy and financial stability. 


\section{A Appendix}

\section{A.1 Proofs of propositions}

Proof of Proposition 1. The homeowner consumption in the no-default state $c_{n d}^{F B}$ is increasing in $\pi: \frac{\partial c_{n d}^{F B}}{\partial \pi}=-\frac{\partial r(\pi)}{\partial \pi} l>0$, as:

$$
\frac{\partial r(\pi)}{\partial \pi}=\underbrace{\left[\frac{E\left[q_{1} h+\left.\xi y_{1}\right|^{\prime} \text { default', } \pi\right]}{l_{0}}-(1+\bar{r})\right]}_{<0} \underbrace{\frac{p^{\prime}(\pi)}{p(\pi)^{2}}}_{>0}<0 .
$$

The value $V_{R}^{F B}(\pi)=E\left[u\left(c_{r}^{F B}\right)+\chi v(h) \mid \pi\right]$ continuous and differantiable by the assumptions made on $u(\cdot)$. It is linearly increasing in type $\pi$ :

$$
\begin{aligned}
\frac{\partial V_{R}^{F B}(\pi)}{\partial \pi} & =u\left(c_{r}^{F B}\left(y_{H}\right)\right)-u\left(c_{r}^{F B}\left(y_{L}\right)\right)>0 \\
\frac{\partial^{2} V_{R}^{F B}(\pi)}{\partial \pi^{2}} & =0 .
\end{aligned}
$$

The value $V_{H}^{F B}(\pi)=E\left[p\left(\hat{\pi}^{F B}\right)\left[u\left(c_{n d}^{F B}\left(\hat{\pi}^{F B}\right)\right)+v(h)\right]+\left(1-p\left(\hat{\pi}^{F B}\right)\right)\left[u\left(c_{d}^{F B}\right)+\right.\right.$ $\left.\chi v(h)] \mid \hat{\pi}^{F B}\right]$ is not necessarily continuous and differentiable everywhere: it can exhibit discontinuous jumps. To see this, define default sets $D(\pi)$ as the set of states $s \in S$ in which a borrower of type $\pi$ ex-post finds it optimal to default:

$$
D(\pi) \equiv\left\{s \in S \mid u\left(c_{d}^{F B}\left(y_{1}^{s} ; \pi\right)\right)+\chi v(h)>u\left(c_{n d}^{F B}\left(y_{1}^{s}, q_{1}^{s} ; \pi\right)\right)+v(h)\right\},
$$

where $y_{1}^{s}$ and $q_{1}^{s}$ denote the realisation of income $y_{1}$ and house value $q_{1}$ in a given state $s$. The default probability $p(\pi)$ is decreasing in $\pi$, which implies that $\pi>\pi^{\prime} \Longrightarrow D(\pi) \subseteq D\left(\pi^{\prime}\right)$. In other words higher types cannot default in strictly more states than lower types; high types are by definition more likely to realise favourable states with $y_{1}=y_{H}$. Finally, when the set of states $S$ is a discrete set, either $D(\pi)=D\left(\pi^{\prime}\right) \forall \pi, \pi^{\prime}$, or $D(\pi) \subset D\left(\pi^{\prime}\right)$ for some $\pi=\pi^{\prime}+\epsilon$ for an arbitrarily small $\epsilon>0$. In the former case, all types default in exactly the same states, and $V_{H}^{F B}(\pi)$ is continuous and differentiable in $\pi$. In the latter case, there are discontinuous jumps at cut-off types where the switch from a default set $D\left(\pi^{\prime}\right)$ to a smaller one $D(\pi) \subset D\left(\pi^{\prime}\right)$ happens. 
However, because utility $u(\cdot)$ is increasing in consumption by assumption, consumption in the no-default state is increasing in $\pi$, consumption in the default state is constant in the type $\pi$, and the no-default probability is increasing in $\pi$, it follows that expected utility is increasing in $\pi$. This directly implies that $V_{H}^{F B}(\pi)$ is always increasing in $\pi$, also at any possible discontinuity points.

Then, there exists a parametrisation (specific functional forms and a set of parameter values) for which the value functions $V_{R}^{F B}(\pi)$ and $V_{H}^{F B}(\pi)$ intersect at most once in the interval $\pi \in[0,1]$. If no intersection exists in this interval, if $V_{R}^{F B}(\pi)<V_{H}^{F B}(\pi) \forall p$, define $\hat{\pi}^{F B}=0$, and if $V_{R}^{F B}(\pi)>$ $V_{H}^{F B}(\pi) \forall \pi$, define $\hat{\pi}^{F B}=1$. I assume that the parametrisation is such that I can rule out cases where the value functions could intersect more than once.

Proof of proposition 2. Similarly to the symmetric information case, the value of a tenant $V_{R}(\pi)$ is linearly increasing in $\pi$ :

$$
\frac{\partial V_{H}(\pi)}{\partial \pi}=u\left(c^{r}\left(y_{H}\right)\right)-u\left(c^{r}\left(y_{L}\right)\right)>0
$$

The value of a home-owner $V_{H}(\pi)$ is increasing in $\pi$ is increasing following the same argument as $V_{H}^{F B}(\pi)$, presented in the proof of Proposition 1 above. Then, there exists a parametrisation (specific functional forms and a set of parameter values) for $V_{R}(\pi)$ and $V_{H}(\pi)$ such that they intersect at most once in the interval $\pi \in[0,1]$. If no intersection exists in this interval and $V_{R}(\pi)<V_{H}(\pi) \forall \pi$, define $\hat{\pi}=0$, and if $V_{R}(\pi)>V_{H}(\pi) \forall \pi$, define $\hat{\pi}=1$.

\section{A.2 Numerical solution algorithm}

The numerical method for finding the equilibrium under a given parametrisation and functional forms is an iteration algorithm based on guessing and iterating on an interest rate until convergence. The algorithm searches for an equilibrium through backward induction, starting from solving the second-period problem of the consumer given the guess for the interest rate, and given this solution, solving the first-period problems of the consumer and the lender. The algorithm proceeds as follows. 
1. Guess for an equilibrium interest rate $r^{*}$.

2. Compute consumption profiles in all different states in $t=1$ and the utilities $u(c)$ from these consumption profiles given the guess for $r^{*}$.

3. Compute the ex-post default decision in $t=1$ of each type $\pi$ for all realisations $\left(y_{1}, q_{1}\right)$.

4. Given the ex-post default choices, compute the ex-ante private default probabilities, expected values $V_{H}$ and $V_{R}$, and tenure choices in $t=0$.

5. Find the cut-off type $\hat{\pi}$ who is indifferent between the expected values $V_{H}$ and $V_{R}$ given the guess $r^{*}$.

6. Given the guess $r^{*}$ and the borrower pool defined by $\hat{\pi}$ implied by the guess, compute the lenders' expected profit.

7. If the lenders' expected profit is not equal to the outside return on funds, adjust the guess $r^{*}$ and iterate until convergence. 


\section{References}

Arslan, Y., B. Guler, and T. Taskin (2015). Joint dynamics of house prices and foreclosures. Journal of Money, Credit and Banking 47, 133-169. Supplement.

Azariadis, C., L. Kaas, and Y. Wen (2016). Self-fulfilling credit cycles. Review of Economic Studies 83, 1364-1405.

Azariadis, C. and B. Smith (1998). Financial intermediation and regime switching in business cycles. American Economic Review 88, 516-536.

Beaudry, P., D. Galizia, and F. Portier (2015). Reviving the limit cycle view of macroeconomic fluctuations. Unpublished manuscript.

Bigio, S. (2015). Endogenous liquidity and the business cycle. American Economic Review 105, 1883-1927.

Corbae, D. and E. Quintin (2015). Leverage and the foreclosure crisis. Journal of Political Economy 123, 1-65.

De Meza, D. and D. C. Webb (1987). Too much investment: a problem of asymmetric information. Quarterly Journal of Economics 102, 281-292.

De Meza, D. and D. C. Webb (1990). Risk, adverse selection and capital market failure. Economic Journal 100, 206-214.

De Meza, D. and D. C. Webb (1999). Wealth, enterprise and credit policy. Economic Journal 109, 153-163.

Dell'Ariccia, G. and R. Marquez (2006). Lending booms and lending standards. Journal of Finance 61, 2511-2546.

Dell'Ariccia, G. and R. Marquez (2012). Credit booms and lending standards: Evidence from the subprime mortgage market. Journal of Money, Credit and Banking 44, 367-384.

Eisfeldt, A. L. (2004). Endogenous liquidity in asset markets. Journal of Finance 59, 1-30.

Elenev, V., T. Landvoigt, and S. Van Nieuwerburgh (2016). Phasing out the GSEs. Journal of Monetary Economics 81, 111-132. 
Favara, G. (2012). Agency problems and endogenous investment fluctuations. Review of Financial Studies 25, 2301-2342.

Favilukis, J., S. C. Ludvigson, and S. Van Nieuwerburgh (2017). Macroeconomic effects of housing wealth, housing finance, and limited risk sharing in general equilibrium. Journal of Political Economy. Forthcoming.

Financial Crisis Inquiry Commission (2011). Final Report of the National Commission on the Causes of the Financial and Economic Crisis in the United States. U.S. Government Printing Office, Washington, DC.

Gorea, D. and V. Midrigan (2015). Liquidity constraints in the U.S. housing market. Unpublished manuscript.

Guerrieri, L. and M. Iacoviello (2014). Collateral constrains and macroeconomic asymmetries. Unpublished manuscript.

Guler, B. (2015). Innovations in information technology and the mortgage market. Review of Economic Dynamics 18, 456-483.

Hayre, L. S. and M. Saraf (2008). A loss severity model for residential mortgages. Journal of Fixed Income 18, 5-31.

House, C. L. (2006). Adverse selection and the financial accelerator. Journal of Monetary Economics 53, 1117-1134.

Iacoviello, M. (2005). House prices, borrowing constraints, and monetary policy in the business cycle. American Economic Review 95, 739-764.

Iacoviello, M. and M. Pavan (2013). Housing and debt over the life cycle and over the the business cycle. Journal of Monetary Economics 60, 221238.

Jokivuolle, E., I. Kiema, and T. Vesala (2014). Why do we need countercyclical capital requirements? Journal of Financial Services Research 46, $55-76$.

Kaplan, G. and G. L. Violante (2014). A model of the consumption response to fiscal stimulus payments. Econometrica 82, 1199-1239.

Kawano, L. and S. LaLumia (2015). How income changes during unemployment: Evidence from tax return data. Unpublished manuscript. 
Kiyotaki, N., A. Michaelides, and K. Nikolov (2011). Winners and losers in housing markets. Journal of Money, Credit and Banking 43, 255-296.

Matsuyama, K. (2007). Credit traps and credit cycles. American Economic Review 97, 503-516.

Matsuyama, K., I. Sushko, and L. Gardini (2016). Revisiting the model of credit cycles with good and bad projects. Journal of Economic Theory 163, 525-556.

Mian, A., K. Rao, and A. Sufi (2013). Household balance sheets, consumption, and the economic slump. American Economic Review 128, 1687-1726.

Mian, A. and A. Sufi (2009). The consequences of mortgage credit expansion: evidence from the U.S. mortgage default crisis. Quarterly Journal of Economics 124, 1449-1496.

Mian, A. and A. Sufi (2011). House prices, home equity-based borrowing, and the US household leverage crisis. American Economic Review 101, 2132-2156.

Morris, S. and H. S. Shin (2012). Contagious adverse selection. American Economic Journal: Macroeconomics 4, 1-21.

Mortgage Bankers Association (2016). MBA residential origination data book. https://www.mba.org/news-research-and-resources/ research-and-economics/single-family-research/ mba-residential-origination-databook-and-reports. Accessed on 29 November 2016.

Ospina, J. and H. Uhlig (2016). Mortgage-backed securities and the financial crisis of 2008: a post mortem. Unpublished manuscript.

Takalo, T. and O. Toivanen (2012). Entrepreneurship, financiership, and selection. Scandinavian Journal of Economics 114, 601-628.

Tirole, J. (2006). The Theory of Corporate Finance. Princeton University Press, Princeton.

Zibel, A. and A. Andriotis (2015). Lenders step up financing to subprime borrowers. Wall Street Journal. 18 February 2015. 